\title{
Ecomorphological analysis of the astragalo-calcaneal complex in rodents and inferences of locomotor behaviours in extinct rodent species
}

\author{
Samuel Ginot ${ }^{\text {Corresp., }}{ }^{1}$ ， Lionel Hautier $^{1}{ }^{\text {， Laurent Marivaux }}{ }^{1}$ ， Monique Vianey-Liaud ${ }^{1}$ \\ ${ }^{1}$ Institut des Sciences de l'Evolution de Montpellier, Université de Montpellier, Montpellier, France \\ Corresponding Author: Samuel Ginot \\ Email address: samuel.ginot@umontpellier.fr
}

Studies linking postcranial morphology with locomotion in mammals are common. However, such studies are mostly restricted to caviomorphs in rodents. We present here data from various families, belonging to the three main groups of rodents (Sciuroidea, Myodonta, and Ctenohystrica). The aim of this study is to define morphological indicators for the astragalus and calcaneus, which allow for inferences to be made about the locomotor behaviours in rodents. Several specimens were dissected and described to bridge the myology of the leg with the morphology of the bones of interest. Osteological characters were described, compared, mechanically interpreted, and correlated with a "functional sequence" comprising six categories linked to the lifestyle and locomotion (jumping, cursorial, generalist, fossorial, climber and semi-aquatic). Some character states are typical of some of these categories, especially arboreal climbers, fossorial and "cursorial-jumping" taxa. Such reliable characters might be used to infer locomotor behaviours in extinct species. Linear discriminant analyses (LDAs) were used on a wider sample of species and show that astragalar and calcaneal characters can be used to discriminate the categories among extant species whereas a posteriori inferences on extinct species should be examined with caution. 
1 Title: Ecomorphological analysis of the astragalo-calcaneal complex in rodents and 2 inferences of locomotor behaviours in extinct rodent species.

3

4 Authors:

5 Samuel Ginot (1)

6 Lionel Hautier (1)

7 Laurent Marivaux (1)

8 Monique Vianey-Liaud (1)

9 (1) Institut des Sciences de l'Evolution de Montpellier, Université Montpellier, CNRS, IRD, Cc

10 064; place Eugène Bataillon, 34095 Montpellier Cedex 5, France

12 Abstract: Studies linking postcranial morphology with locomotion in mammals are common.

13 However, such studies are mostly restricted to caviomorphs in rodents. We present here data

14 from various families, belonging to the three main groups of rodents (Sciuroidea, Myodonta, and 15 Ctenohystrica). The aim of this study is to define morphological indicators for the astragalus and 16 calcaneus, which allow for inferences to be made about the locomotor behaviours in rodents. 17 Several specimens were dissected and described to bridge the myology of the leg with the 18 morphology of the bones of interest. Osteological characters were described, compared, mechanically interpreted, and correlated with a "functional sequence" comprising six categories linked to the lifestyle and locomotion (jumping, cursorial, generalist, fossorial, climber and semiaquatic). Some character states are typical of some of these categories, especially arboreal climbers, fossorial and "cursorial-jumping" taxa. Such reliable characters might be used to infer locomotor behaviours in extinct species. Linear discriminant analyses (LDAs) were used on a wider sample of species and show that astragalar and calcaneal characters can be used to 25 discriminate the categories among extant species whereas a posteriori inferences on extinct species should be examined with caution. 


\section{Introduction} order (e.g., Wilson and Reeder, 2005). Aside from this specific diversity, rodents occupy a wide array of ecological niches, from aquatic environments to desert areas, and this is notably reflected in the diversity of their locomotor and positional behaviours, which are associated with various types of locomotory apparatus. Most rodents are very versatile in terms of locomotion and are capable of using a variety of motions (e.g., jumping, running, climbing, or swimming). Highly specialized species are usually still able to switch from one type of locomotion to another (e.g., squirrels can climb a vertical support or run on a horizontal one, gerboas can use jumping running or quadrupedal walking). Other behaviours involving the limbs, such as digging and food handling, must also be considered since they influence the morphology as well as the modalities of locomotion (e.g., running while carrying food or moving around in a burrow). Despite their geographical and taxonomic distance, some rodent communities converge in morphology and types of locomotion. One striking example is that of desert rodents, which display the same types of morphological adaptations on different continents, due to adaptive convergence linked to similar ecological and environmental constraints (Eisenberg, 1975). cranial morphology. Although this relationship has been investigated in several mammalian groups, primarily in primates (e.g., Gebo, 1988; Gebo et al. 1991; Strasser 1992) but also marsupials (e.g., Szalay, 2006), studies regarding rodents are still limited (e.g., Szalay, 1985; Vianey-Liaud et al., 2015). Most have been focusing solely on caviomorphs (e.g., Biknevicius, 1993; Weisbecker and Schmid, 2007; Lessa et al., 2008; Candela and Picasso, 2008; Morgan, 2009; Elissamburu and De Santis, 2011), mostly because they display a wide array of ecological niches due to their long and isolated evolutionary history in South America (e.g., Biknevicius, 
63 2009; Elissamburu and De Santis, 2011). Two notable exceptions, combining numerous species

64 from the three main clades of rodents with some fossil species, are found in Samuels and Van 65 Valkenburgh (2008) and Vianey-Liaud et al. (2015). Most of these articles focus on the girdles 66 and/or limbs as a whole. However, one of the most important regions in locomotion, as well as 67 other related behaviours, is the ankle joint, and chiefly the calcaneus and astragalus. Indeed, these two bones form the fulcrum (astragalus) and lever arm (calcaneus) of the foot, when taken as a lever system (Carrano, 1997; Davidovits, 2012). More interestingly, the calcaneus and astragalus are frequently found in the fossil record. Despite the pivotal roles of these two bones, and regardless the extreme diversity of the order, only a handful of studies has attempted to describe in detail the astragalo-calcaneal complex in rodents (e.g., Szalay, 1985; Candela and Picasso, 2008; Vianey-Liaud et al., 2015). species.

\section{Material and methods}

This study aims to determine how locomotion imprints the morphology of the astragalus and calcaneus (especially the calcaneo-astragalar joint). This is crucial since the shape of these two bones largely brackets the array of possible movements of the foot. In several taxa, comparable characters are described qualitatively, so that their variation can be functionally interpreted. This allowed us to define character states that best characterize the motion range of the ankle, and the favoured locomotor mode as a result. Legs were dissected in a few species in order to clarify the functional link between bones and muscles. Finally, we employed multivariate analyses on a larger dataset to infer the locomotory behaviours of some fossil

\section{Material and methods}

Qualitative analyses - Precise anatomical descriptions were made on a total sample of 17 species in as many genera. These species were selected to represent a large panel of locomotor modes in several different families of rodents, to potentially detect convergent characters. To limit the bias of different stages of ossification, we used adult complete specimens, or, when isolated calcanei and astragali were studied, they were fully ossified. Osteological nomenclature was derived from Szalay (1985). Classification follows Fabre et al. (2012). 
94 genera from the Muséum National d'Histoire Naturelle (MNHN) in Paris, France (Ctenohystrica: 95 Myocastor coypus MNHN 1959-148; Squirrel-related clade: Pteromys volans MNHN 1929-433, 96 Marmota marmota MNHN 1933-277, Sciurus vulgaris MNHN 2000-407; Myodonta: Spalax 97 ehrenbergi MNHN 200-353, Jaculus sp. MNHN A12-495).

Eleven more astragali and calcanei of eleven other species in ten genera were sampled in 99 the collections of the Université de Montpellier (UM), housed at the Institut des Sciences de 100 l'Evolution de Montpellier (ISE-M), France (Ctenohystrica: Proechimys cuvieri UM 1054 V, 101 Cavia porcellus UM 558 V, Chinchilla lanigera UM 498 V, Octodon degus UM 500 V, 102 Coendou prehensilis N-481, Ctenodactylus vali UM 709 N; Squirrel-related clade: Spermophilus 103 fulvus UM 280 N; Myodonta: Psammomys obesus UM 577 N, Microtus gregalis N-420, 104 Gerbillus sp. UM 576 N, Castor sp. UM 055 V).

105 Six of these eleven specimens were already cleaned, the other five (C. lanigera, C. vali, 106 Gerbillus sp., P. cuvieri and P. obesus) were complete animals fixed in formal saline (buffered $1074 \%$ formaldehyde solution with $0.12 \mathrm{M} \mathrm{NaCl}$ ) and stored in $70 \%$ ethanol. Their hindlimbs were 108 dissected and cleaned to get the astragalus and calcaneum, as well as to clarify the links between 109 these bones and the muscular and ligamentary systems of the leg at the level of the ankle. Since 110 the myology of the leg in these species had not yet, to our knowledge, been studied, 111 identifications of muscles, ligaments, and other structures during dissections was based on 112 comparisons with reports by Klingener (1964; Dipodoidea), Brannen (1976; Mus musculus), and 113 Hildebrand (1978; diverse taxa). In all dissections, one leg was cut off the specimen (except for 114 Proechimys cuvieri, in which the state of conservation required dissecting both legs, without 115 cutting them off) and some of the most proximal muscles were also cut in the process (e.g., 116 Biceps femoris and vastus lateralis) and could not be described precisely. However, since the 117 main interest here is the calcaneo-astragalar complex, we focused on muscles that show direct 118 connection to these bones (biceps femoris and vastus lateralis, gastrocnemius, soleus, tibialis 119 cranialis and extensor digitorum longus, peroneus longus and brevis, and flexor fibularis). For 120 the five species that were dissected, the origin and insertion of the muscles connected to the 121 astragalus and calcaneus are summed up in Supp. material Table 1. The insertions of tendons and 122 ligaments on the calcaneus and astragalus are summed up in Figure 1. Once the legs were 123 dissected, and the calcaneus and talus were cleaned of the remaining soft tissues, the osteological 124 characters were studied qualitatively as with aforementioned specimens that were already 
125 cleaned. All abbreviations are summed up in appendix 1.

126

127

128

129

130

131

132

133

134

135

136

137

138

139

140

141

142

143

144

145

146

147

148

149

150

151

152

153

154

155

Locomotory categories - Following Elissamburu and Vizcaino (2004), a "functional sequence" is proposed, as follows: 1, "jumper" (C. lanigera and Jaculus sp.), includes species that use mainly hindlimb driven jumps to move around (either bipedal or quadrupedal) ; 2, "cursorial" (Gerbillus sp. and M. coypus), includes quadrupedal running taxa ; 3, "generalist" $(P$. cuvieri, C. gundi, C. porcellus and $O$. degu), this category contains quadrupedal ground dwellers that are also know to commonly climb or dig burrows ; 4, "fossorial" (M. marmota, M. gregalis, P. obesus, S. fulvus and S. ehrenbergi), includes adept diggers that are partly or fully fossorial ; 5, "climber" (S. vulgaris, P. volans, and C. prehensilis), includes tree-dwelling taxa that are specialized in climbing. ; 6, "semi-aquatic" (M. coypus and Castor sp.), with taxa that spend a large part of their time in water, and are known to be good swimmers. The placement of each taxa in the different categories derives from the available literature dealing with the ecology and behaviours (categories and refs. are provided in Table 1). Qualitative characters were observed and correlated with their behaviours and with the sequence.

Quantitative analyses - Fourty-two more specimens (representing 19 additional species) were sampled from the MNHN collection and used in Linear Discriminant Analyses (LDA), altogether with the taxa that were described in full details. Overall, 56 specimens in 35 species were used in the LDA. All individuals, as well as their locomotor group are listed in Tab. 1. For all individuals, 16 linear measurements were taken on the calcaneus and 22 on the astragalus (all measurements are shown in Fig. 2, and their values for each specimen are listed in the supplementary material, Table 2). For the astragalus, however, some measurements presented in Fig. 2 (c1, c2, d1, d2, ITAH and mTAH) were not used in the following analysis, since they did not represent curvature precisely. Thus, we also used 16 measurements for the astragalus in our analysis. When several specimens were available for one species, the species' average for each measurement was calculated. Some of the measurements were taken from Candela \& Picasso (2008), while the rest were created to describe the morphological variation of the bones thoroughly, with regard to function, based on the qualitative characters. To remove the effect of size from the analysis, all linear measurements of each individual (or the average when several specimens were measured for one species) were divided by the corresponding geometric mean, 
156 and a log function was used to produce log shape ratios (Claude, 2008). The categories of the 157 functional sequence were also used in these analyses. Calcanei and astragali were treated 158 separately in order to check for differences in the signals between the astragalus and the 159 calcaneus, as well as to allow us to use fossil specimens, for which bones are often found 160 isolated. For both the astragalus and calcaneus, MANOVAs were run to test for effects of 161 locomotion and phylogeny. Morphological variables that had no correlation with any linear 162 discriminant functions were not used in the MANOVAs.

163 Fossil taxa from the UM collections were added a posteriori in the analyses 164 (Theridomyidae: Blainvillimys langei RAV2001 and RAV2002, Pseudoltinomys gaillardi 165 RAV2003 and RAV2004, Issiodoromys pauffiensis SPV593, SPV592 and MPF213; Sciuridae: 166 Palaeosciurus goti MGB101 and MGB102; Cricetidae: Eucricetodon atavus RAV2005 and 167 RAV2006). These specimens are all from French Oligocene deposits of the Quercy area 168 (localities Ravet, Mas-de-Got-B and Mas-de-Pauffié). Taxon identification is based on faunal 169 lists from these localities and comparison with material represented in Vianey-Liaud et al. 170 (2015). Post-cranial remains of B. langei, P. gaillardi and I. Pauffiensis are described in Vianey171 Liaud et al. (2015) and details on P. goti can be found in Vianey-Liaud (1974). Both these papers 172 present hypotheses regarding the locomotion of these taxa. The specimens used here were 173 selected to test these hypotheses, as well as to check how well can quantitative analyses predict 174 locomotory behaviour in fossil group with extant representatives (P. goti, E. atavus) or not (B. 175 langei, P. gaillardi and I. Pauffiensis).

176 For a more synthetic view, all the specimens (extant and extinct) are listed in Table 1. All 177 analyses were performed with R (R Core Team 2015), using the function lda of package MASS 178 (Venables and Ripley, 2002)

Results

181

\section{Osteological descriptions}

183 This part includes descriptions of the astragali and calcanei of four species in three 185 families from the Myodonta (Muridae, Cricetidae and Spalacidae), six species in five families 186 from Ctenohystrica (Ctenodactylidae, Cavidae, Erethizontidae, Octodontidae and Chinchillidae) 
187 and four species in one family from the squirrel-related clade (Sciuridae) (Fabre et al. 2012). In

188 cases where several species were described in the same family, only one comparative description 189 was made. When only one species was available for a said family, this species was described in 190 full details.

Four sciurid representatives were considered: Marmota marmota Linnaeus, 1758 (Fig. 3A) and Spermophilus fulvus Lichtenstein, 1823 (Fig. 3B) (both terrestrial squirrels from the Xerinae), and Sciurus vulgaris Linnaeus, 1758 (Fig. 3D) and Pteromys volans Linnaeus, 1758 (Fig. 3C) (both tree-dwelling squirrels from the Sciurinae).

Calcaneus. The ectal facet of the calcaneus is generally long and helical, but much less so in the alpine marmot. The sustentacular facet has a round shape in ground species, while it is rather triangular in climbers, furthermore it is slightly concave in all species except $M$. marmota. Both facets are always separated by a distinct sulcus (Fig. 1A). In all species, the peroneal process is well-developed and in a posterior position. This is particularly true in climbing squirrels ( $P$. volans and $S$. vulgaris), in which the peroneal process is even more posterior than the sustentacular process (also noted in Emry \& Thorington 1982 and Thorington et al. 2005). The position of the peroneal process and the importance of its groove are linked to the various movements of the peroneus muscles tendons (Fig. 1). The neck of the calcaneus is long and narrow, and curved medially, with the exception of the marmot, in which it is wider and less curved. The tuber calcanei show to distinct crests. In all species, except M. marmota, the medial crest is more developed than the lateral one, and it slightly projects medially. The body is rather short in the two ground squirrels, and longer in the climbers, especially $P$. volans. In plantar

211 view, the anterior plantar tubercle is well-developed in the ground squirrels only. The groove for 212 the flexor fibularis muscle (Fig. 1) is deeper and wider in ground squirrels than in climbers. 213 Finally, the calcaneo-cuboid facet is generally round and concave in all species, but it is slightly 214 more ovoid in the alpine marmot.

215 Astragalus. The sides of the astragalar trochlea are always asymmetrical, but more so in $216 S$. vulgaris and P. volans. The groove of the trochlea is also shallower and narrower in these 217 latter species, compared to the ground squirrels. The neck is generally long and it deviates 
218 medially, particularly in climbers. The head of the astragalus is rather wide and round, but the

219 astragalo-navicular facet is saddle-shaped in both S. vulgaris and P. volans (contrary to Emry \&

220 Thorington 1982, who restricted this character to the Sciurini). The AmT facet is generally well-

221 developed on the medial side of the neck, but is also more developed on the dorsal side of the

222 neck in climbers. On the plantar side, the sustentacular and ectal facets are oriented mainly

223 antero-posteriorly in the ground squirrels, while they are obliquely oriented in the tree squirrels.

224 Furthermore, a sulcus is always present between the facets (Fig. 1B), except in P. volans. The

225 sustentacular facet joins the AN facet in the climbers, while they are separated in the ground

226 squirrels. Although the medial plantar tuberosity is developed in all species, it is very prominent

227 and forms a "hook" in the tree squirrels. On the medial and lateral sides, it appears that the sides

228 of the trochlea are more curved in ground squirrels than in tree squirrels.

229

230

Muridae Illiger, 1811. (Fig. 4E-F)

231

232

Two murid representatives are described: Gerbillus sp. Desmarest, 1804 (Fig. 4E), and

233

Psammomys obesus Cretzschmar, 1828 (Fig. 4F). Both are members of the Gerbillini tribe in the

234

Gerbillinae subfamily.

235

Calcaneus. The ectal facet of the calcaneus is strongly convex in both species, but longer

236

in P. obesus. Both species show an ovoid sustentacular facet, slightly smaller in P. obesus. The

237

neck of the calcaneus is straight in both species, and narrower and longer in Gerbillus sp.. In

238

both species, the tuber shows a well-developed medial posterior crest, while the lateral side is

flatter. P. obesus also shows a shallow fossa on the medial side of the neck, and a deep and ovoid

one on the lateral side, allowing strong attachment of the ligament linking the calcaneus to the crus. The body is elongated, and slightly widened in P. obesus. In both species the calcaneo-

cuboid facet is large and bean-shaped. In Gerbillus sp. this facet is obliquely oriented, the lateral edge being more distal than the medial edge. Differences are notable in plantar view in Gerbillus sp. The groove for the flexor fibularis muscle is deep, while it is shallow in P. obesus. Furthermore, the anterior plantar tubercle is well-developed and projected anteriorly in Gerbillus sp. while it is rather weak in P. obesus. The peroneal process is not developed in Gerbillus sp. and only slightly more in P. obesus. However, in both cases it bears a well-defined groove for the passage of the peroneus muscles. In both species, the peroneal process is placed very distally 
249

250

251

252

253

254

255

256

257

258

259

260

261

262

263

264

265

266

267

268

269

270

271

272

273

274

275

276

277

278

279

on the body of the calcaneus.

Astragalus. The trochlea is asymmetrical and very wide in both species. The groove between sides is shallow, with Gerbillus sp. being slightly deeper. Both species show a pit at the base of the medial ridge of the trochlea. The neck is wide and moderately long in both species, however it is only deflected medially in P. obesus., The head is wide and the AN facet is developed on the dorso-lateral part of the neck. Similarly, the AmT facet is well-developed on the lateral side of the neck. In plantar view, the ectal facet is wide in both species, but projects more laterally in Gerbillus sp.. The sustentacular facet is small, ovoid and oriented anteroposteriorly in both species. The ectal and sustentacular facets are separated by a wide sulcus, and so are the sustentacular and AN facets. In both species, the body is deep, with curved sides of the trochlea. In Gerbillus sp. the curvature is greater on the lateral side, while the reverse is true for P. obesus.

\section{Cricetidae Fischer, 1817. (Fig. 4G)}

\section{Microtus gregalis (Arvicolinae, Arvicolini) Pallas, 1779. (Fig. 4G)}

Calcaneus. The ectal facet of the calcaneus is short, convex and oriented medially. The sustentacular facet is ovoid in shape, elongated on an anteromedial to posterolateral axis. The sustentaculum is projected in its posterior part. The body and neck are thick, the neck widening posteriorly. The medial posterior crest of the tuber is salient, contrary to the lateral one. The peroneal process in $M$. gregalis has a peculiar shape compared to other taxa studied here, being strongly developed laterally and elongated anteroposteriorly, with a dorsal crest projected in its most posterior part. It is extremely distal, the edge being more distal than the surface of the calcaneo-cuboid face, while the posterior extremity is more distal than the fossa at the base of the ectal facet. The lateral groove of the process is wide and well-marked. The calcaneo-cuboid facet is enlarged transversely and in its plantar part. In plantar view, the anterior tubercle is small, but the groove for the flexor fibularis is present on the lateral part of the sustentaculum.

Astragalus. The astragalar trochlea is asymmetrical and the groove between the rims is shallow. The neck is moderately long and very slightly deflected medially. There is a welldefined protuberance in the middle of its dorsal aspect (probably a "tibial-stop"). The astragalonavicular facet is slightly convex, and its lateral edge is projected laterally. The AmT facet is not 
280 visible in dorsal view. On the plantar side, the ectal facet is long and has a crescent shape. It is

281 slightly oriented towards the lateral side, and the distal part is projected laterally; it is also 282 strongly curved. The sustentacular facet is ovoid, oriented anteroposteriorly, and clearly 283 separated from the other plantar facets by a very wide and deep sulcus). The proximo-plantar 284 edge of the trochlea is salient, but only where it joins the ectal facet. The medial tuberosity is 285 rounded. The AmT facet can be seen in plantar view; it is narrow and elongated on the medial 286 287 part of the neck. In lateral and medial views, the trochlea displays a very low radius of curvature, and its body is deep. especially in its posterior part. On the plantar side and anterior to the tuber, a clear protuberance allows the insertion for the short plantar muscles (Supp. material, Tab. 1). The ectal facet is short, convex, and entirely oriented medially. The sustentacular facet is reduced and clearly curved medially. The posterior edge of the sustentaculum joins the edge of the ectal facet. The groove between the ectal and sustentacular facets is weakly marked. The peroneal process is well-developed and distal-most. The anterior plantar tubercle is developed, medially positioned, and meets the edge of the calcaneo-cuboid facet. The groove for the flexor fibularis is wide but moderately deep. These characters are consistent with the development of a powerful musculature for the movements of the foot.

Astragalus. The astragalar trochlea is symmetrical; the groove is almost non-existent (flat trochlear surface). The neck is long, but only slightly deflected medially, and the head is large and spherical. On the plantar side, the ectal facet is reduced in its distal medial part and somewhat curved. The sustentacular facet is short and oriented anteroposteriorly, although it is prolonged medially in its distal part, therefore joining the AmT facet. The sulcus between the ectal and sustentacular facets is short and shallow, but wide. The trochlea is moderately curved on both sides, and its body is deep. 
Jaculus sp. (Dipodinae) Erxleben, 1777. (Fig. 4I)

Calcaneus. On the calcaneus, the ectal and sustentacular facets are concave and oriented almost perpendicularly to the major axis of the bone. Therefore, the astragalus interlocks into these facets, which limits or potentially stops any movement of one bone independently of the other. The body of the calcaneus and the calcaneo-cuboid facet are narrow and oriented dorsoplantarly. The neck is long and moderately deep. The sustentaculum and the medial tarsal form a continuous surface, which strongly maintains the astragalus in place. The groove for the

319 flexor fibularis is well-marked. The peroneal process is reduced to a weak groove, reflecting the reduction of the fibula, almost fused with the tibia.

Astragalus. Both sides of the astragalar trochlea are only slightly asymmetrical, and the groove between them is deep, thereby limiting movements in a parasagittal plane. Just distally to the base of the trochlea are two pits, which correspond to the contact with the anterior distal edge of the tibia during dorsiflexion of the foot. The neck is extremely short, almost non-existent, and the head is narrow and in line with main axis of the bone. On the plantar side, the sustentacular facet is oriented anteroposteriorly, extending from the plantar edge of the trochlea to the astragalo-navicular facet. The ectal facet also has a particular shape: it is strongly curved and occupies the whole lateral side of the astragalus. Its anterior part is also strongly projected laterally. During the joint movements, this lateral astragalar process remains in contact with the base of the calcaneal ectal facet. In lateral view, the trochlea is curved; it is slightly less in medial 331 view.

In this taxon it seems that both bones form one tightly fitted unit, with very little independent movements from one another.

Calcaneus. The ectal facet of the calcaneus is short, convex, and in its anterior lateral extremity is projected laterally. The sustentacular facet is small with a slightly concave anterior part. The two facets are merged, without apparent limit or groove. Furthermore, the body of the bone is wide, suggesting an efficient support as well as mobility for the astragalus. The peroneal 
342 process is moderately developed, distally positioned and bears a well-defined groove; as a whole

343 it looks similar to that of Coendou prehensilis.

344 Astragalus. The trochlea is asymmetrical and only slightly grooved. The neck is long 345 (but less than in squirrels), and clearly deflected medially. The head is wide and rounded in its 346 medial part. On the plantar side, the ectal and sustentacular facets are merged together, forming a 347 smooth surface transversely oriented. The ectal part of the surface is somewhat curved, 348 especially posteriorly. The articular surface of the sustentacular part is developed on the neck but 349 does not reach the astragalo-navicular facet. The plantar medial tuberosity is prominent and 350 hook-shaped, which articulates with the posterior edge of the sustentaculum. In medial and 351 lateral views, the trochlea is moderately curved, and the body is deep.

352

Caviidae Waterhouse, 1829. (Fig. 5K)

354

355

356

357

358

359

360

crescent-shaped, and its dorsal tip is more anterior than the plantar one. It is somewhat similar to what can be observed in some artiodactyls such as cows or goats. The groove for the flexor fibularis is deep, in relation with powerful toe flexing muscles. The peroneal process is absent and only a weak groove can be found on the anterior lateral side of the bone.

Calcaneus. The ectal facet of the calcaneus is convex and short. The surface of the sustentacular facet is parallel to the major axis of the bone. Both facets are in contact, although the limit between them can easily be identified. The neck is straight, narrow and deep. The body of the bone is oriented dorso-plantarly, as is the calcaneo-cuboid facet. This facet is also

Astragalus. The astragalar trochlea is slightly asymmetrical, with a wide but moderately deep groove. The neck is very short and barely deflected medially. At the base of the central part of the trochlea, a deep and wide fossa allows the articulation with the anterior distal process of the tibia during dorsiflexion of the foot. The astragalo-navicular extends dorsally and projects laterally. In dorsal view, only the medial edge of the AmT facet is visible. In plantar view, the ectal facet is strongly concave and wide, in particular in its central part. It is also noticeably projected laterally in its anterior part. The sustentacular facet is long, joining distally the astragalo-navicular facet. It is separated from the ectal facet by a wide sulcus. The proximoplantar edge of the trochlea is not salient, except at the level of the ectal facet, and there is no 
373 medial tuberosity. The AmT is short and clearly seen in medial and plantar view. The trochlea is

374 slightly curved on both sides.

375

376

377

378

379

380

381

382

383

384

385

386

387

388

389

390

391

392

393

394

395

396

397

398

399

400

401

402

403

Astragalus. The astragalar trochlea is slightly asymmetrical, with a deep groove between the two salient ridges. The neck is short and barely deflected medially. The astragalo-navicular facet is developed on the dorsal aspect of the neck, while the AmT facet is not visible. The dorsal aspect of the neck also bears a narrow transverse protuberance extending on the whole width of the neck, which is probably a tibia stop. On the plantar side, both the ectal and sustentacular facets are elongated anteroposteriorly, and separated by a deep and wide sulcus. The sustentacular facet extends all along the neck and joins the astragalo-navicular facet. The ectal facet is projected laterally and is strongly concave. The AmT facet is visible and developed on the anterior part of the plantar side of the neck. Both sides of the trochlea are moderately curved. Furthermore, in lateral view, the ectal facet occupies most of the lateral side of the body.

Erethizontidae Bonaparte, 1854. (Fig. 5M)

Chinchilla lanigera Molina, 1782. (Fig. 5L) sustentacular facet is concave and extended anteriorly. The body and neck of the bone are aligned and similar in width. The calcaneo-cuboid facet is very oblique, turned towards the sustentaculum medially. In anterior view, it is oriented anteroposteriorly and crescent-shaped. In plantar view, the groove for the flexor fibularis is narrow and moderately deep. The anterior plantar tubercle is marked and splits anteriorly into two protuberances of similar size. The peroneal process is reduced to a weak groove at the distal extremity of the lateral side of the bone.

\author{
Futhemore, in lateral view, the ectal facet occupies most of the lateral side of the body.
}

Chinchillidae Bennett, 1833. (Fig. 5L)

Calcaneus. The ectal facet of the calcaneus is convex and moderately long. The 
404 widens posteriorly. It is slightly curved towards the medial side (reminiscent of Sciurus and 405 Pteromys) and is particularly tall in medial or lateral view. The medial crest of the tuber is salient 406 and projected medially. The body is short and wide. The peroneal process is well-developed 407 laterally, adding to the width of the body, but also anteroposteriorly. It is in a distal position and 408 bears a marked groove, visible in plantar view. The calcaneo-cuboid facet is somewhat oblique 409 in dorsal view; its lateral edge is more anterior than the medial one. In anterior view, it is 410 concave, with an almost circular shape, widening medially. On the plantar side, the medial distal 411 part of the neck bears a strong protuberance, on which Achilles tendon inserts and the short 412 flexor muscle of the toes originates. The anterior plantar tubercle is marked, but does not 413 protrude much. The groove for the flexor fibularis is moderately deep, but very wide.

Astragalus. The body of the astragalus is much wider than long. Both rims of the trochlea are asymmetrical, with a wide and moderately deep groove in-between. The neck is 416 short and strongly deflected medially. The head is spherical, and the AmT and astragalo417 navicular facets join and form a circular surface. In plantar view, the ectal facet is wide and long, 418 but only slightly curved. The sustentacular facet is long, wide and oriented towards the medial 419 side, extending on the neck and barely joining the astragalo-navicular facet. The sulcus between 420 the ectal and sustentacular facets is marked, but short and narrow, probably allowing important 421 transverse movements. The plantar edge of the trochlea is not salient and there is no clear medial 422 tuberosity. The medial side of the trochlea is somewhat curved, but less than the lateral side. The 423 body is tall on both sides. Overall, the astragalus of $C$. prehensilis is quite typical of erethizontid 424 morphology (Candela and Picasso 2008).

425

Octodontidae Waterhouse, 1839. (Fig. 5N)

427

Calcaneus. The ectal facet of the calcaneus is long and weakly convex; its medial edge is delineated by a marked groove. The sustentacular facet is medium-sized, ovoid (the major axis being oriented anterolateral to posteromedial), and almost flat. Both facets are widely separated.

432 The neck is short and widens posteriorly. The medial posterior crest of the tuber is slightly more 433 developed than the lateral one. The body is long and relatively flat (with the exception of a sub434 ectal fossa) and widens anteriorly. The peroneal process is developed and occupies a distal 
435 position. It bears a shallow groove, which is visible in plantar view. The calcaneo-cuboid facet is 436 slightly turned towards the sustentaculum medially. In anterior view, it has a crescent shape, with 437 a noticeable enlargement in its dorsal part. The groove for the flexor fibularis is wide but 438 moderately marked. The anterior plantar protuberance is not developed.

Astragalus. The astragalar trochlea is slightly asymmetrical, with a deep groove. The neck is quite long and displaced medially. The astragalo-navicular facet is developed on the dorsal part of the neck, in particular laterally. In plantar view, the ectal facet is clearly curved, longer than wide, but with an important lateral projection. The sustentacular facet is somewhat oval-shaped and oriented anteroposteriorly. It is separated from the ectal facet by a deep and wide sulcus, and does not join the astragalo-navicular or AmT facet. The plantar edge of the trochlea is not salient, with a small medial tuberosity. In lateral and medial views, the trochlea is quite curved, and the body is deep.

447

448

449

450

451

452

453

454

455

456

457

458

459

460

461

462

463

464 465

Echimyidae Gray, 1825. (Fig. 5O-P)

Myocastor coypus Molina, 1782. (Fig. 5O)

Calcaneus. The calcaneus has a very unique morphology. The bone is massive, with a compact neck and tuber. The ectal facet is wide, long, and almost parallel to the medial side of the neck. It is concave at its base, but becomes convex in its posterior part. The sustentacular facet is slightly concave and parallel to the main axis of the bone. Both facets are widely separated by a groove. The groove for the flexor fibularis is also very deep, suggesting this muscle is strong. The peroneal process is rather reduced. The calcaneo-cuboid facet is distally positioned onto the long body, obliquely oriented towards the medial side. The anterior plantar tubercle is not prominent.

Astragalus. The astragalar trochlea is slightly asymmetrical and deeply grooved. At the base of the medial side is a cotylar fossa, distally bordered by an osseous bead, which stops the tibia during dorsiflexion of the foot. The neck is very short and slightly defected medially. On the plantar side, the sustentacular facet is wide and oriented anteroposteriorly; it meets the AmT facet medially. The ectal facet is very wide and projects laterally in its anterior part. It is also weakly curved, oriented obliquely, and faces the lateral side, which corresponds to the orientation of the calcaneal ectal facet. The posterior edge of the ectal facet directly meets the 
466 plantar edge of the trochlea, which does not overhang the facets. There is a deep, long and 467 oblique (posteromedial-anterolateral) sulcus between the ectal and sustentacular facets. Both 468 sides of the trochlea are weakly curved, and its body is tall.

469

470

471

472

473

474

475

476

477

478

479

480

481

482

483

484

485

486

487

488

489

490

491

492

493

494

495

496

Proechimys cuvieri Petter, 1978. (Fig. 5P)

Calcaneus. The ectal facet of the calcaneus is short and convex, its posterior part turns medially. The sustentacular facet is small, circular and slightly concave. The sustentaculum is, however, well-developed and projected anteriorly. Both facets are separated by a wide groove. The body and neck are of similar widths. The posterior medial crest of the tuber is very salient, contrary to the lateral one. The body is longer than wide. In dorsal view, the calcaneo-cuboid facet is very oblique, turning towards the medial side. In anterior view, it is deep but narrow, and bean-shaped. The peroneal process is extremely distal and almost joins the lateral edge of the calcaneo-cuboid facet. It is small, but clearly recognizable, forms a half-circle on the lateral side of the bone, and bears a wide but shallow groove. In plantar view, the lateral distal part of the bone is concave, a condition which is found only in this taxon. According to the dissection of the specimen (see Supp. material, Tab. 1), a short muscle originates in this concavity, which inserts on the tendon of the first toe flexor muscle. Considering the direction and insertion of this muscle, it probably is an adductor for the first toe. The anterior plantar tubercle is weak, but the groove for the flexor fibularis is well-marked in a lateral position on the plantar side of the sustentaculum.

Astragalus. The astragalar trochlea is slightly asymmetrical and only slightly grooved. The medial rim is curved medially in its posterior part. The neck is short and slightly deflected medially. The astragalo-navicular is slightly convex and extends on the dorsal aspect of the neck. The AmT facet is limited on the dorsal side of the neck, but broadly developed on the plantar and medial sides. On the plantar side, the ectal facet is long, wide and curved, and its anterior part projects laterally. The proximo-plantar edge of the trochlea is salient but there is no clear medial tuberosity. The sustentacular facet is small, ovoid and oriented anteroposteriorly. It is separated from the ectal facet by a deep and very wide sulcus, and almost in contact with the AmT facet. The latter is narrow and elongated on the plantar side of the neck. In lateral view, the ectal facet occupies most of the side of the astragalar body, which is tall. The lateral and medial sides are strongly curved. 
Remark. Although members of the same family, P. cuvieri and M. coypus do not exhibit

500 facet and the development of the astragalo-navicular facet on the dorsal side of the neck.

501 However, they are also shared with more distant taxa (e.g. O. degus, C. lanigera, Jaculus sp.),

502

503

504

505

506

507

508

509

510

511

512

513

514

515

516

517

518

519

520

521

522

523

524

525

526

527

and probably reflect similar constraints during movements of the foot. This morphological heterogeneity can be explained by the uniqueness of the astragalus and calcaneus of M. coypus.

\section{Castoridae (Fig. 5Q)}

\section{Castor sp. (Fig. 5Q)}

Calcaneus. The ectal facet is short, oriented towards the medial side, and projected plantarly. The sustentacular facet is particularly long and slender, concave, and it is oriented obliquely. Both facets are separated by a deep and wide sulcus. The sustentacular process is projected plantarly. The neck is slender, but very developed dorso-plantarly. In particular, the plantar side forms a strong ridge that is projected medially. The tuber does not show developed medial or lateral ridges, however, there is a marked fossa at the insertion of the Achilles tendon (Fig. 1). The body is rather short, with an large fossa on the lateral side. The lateral part of the body is also projected distally. The calcaneo-cuboid facet has a left-arrow shape. In dorsal view, it is oriented obliquely and in line with the sustentacular facet. The groove for the flexor fibularis (Fig. 1) is deep and wide. The anterior plantar tubercle is present but not prominent. The peroneal process is developed and very distally placed. It bears a wide groove for the tendons of the peroneus muscles.

Astragalus. The trochlea of the astragalus is very wide and asymmetrical, the lateral side being larger than the medial side. However, the groove between the two sides is very shallow. The neck is short and wide; it is also slightly deviated medially. It bears a short ridge on the lateral side. The head is wide and the AN facet is convex and ovoid in shape. The AmT facet is long and comes all the way along the medial side of the neck. On the plantar side, the ectal facet is very wide, but not much curved. The sustentacular is very long, with an oblique medioproximal to latero-distal axis. It joins with the AN facet on the lateral plantar side of the head. The ectal and sustentacular facets are separated by a wide and deep sulcus. The medial part of 
528 the astragalar body forms a process not seen in any other species studied here. The proximal

529 extremity of the sustentacular facet is placed on the plantar side of this process. The body of the astragalus is not deep, and the sides of the trochlea have medium curvature.

531

532 Quantitative analyses

533

534

The linear discriminant analyses (LDA) succeeded at separating the different locomotor

535 groups, with some differences between the astragalus (Fig. 6) and calcaneus (Fig. 7). The effects of locomotion and phylogeny were significant in the analyses. About $40 \%$ of the taxa were assigned to their correct locomotor group when using leave-one-out cross validation.

In both the calcaneus and the astragalus analyses (Fig. 6 and 7), the three jumping taxa (Chinchilla lanigera, Jaculus sp., and Pedetes capensis) are always found apart from all other categories. The climbers (Anomalurus derbianus, Capromys pilorides, Coendou prehensilis, Erethizon dorsatum, Funisciurus anerythrus, Pteromys volans, Ratufa bicolor, Ratufa indica, and Sciurus vulgaris) and fossorial/semi-fossorial (Marmota marmota, Microtus gregalis, Psammomys obesus, Spalax ehrenbergi, and Spermophilus fulvus) taxa are well-discriminated from cursorial (Cavia porcellus, Dolichotis patagonum, Dolichotis sp., Gerbillus sp., Lagidium peruanum, and Proechimys cuvieri), generalist (Atherurus africanus, Ctenodactylus gundi, Ctenodactylus vali, Cuniculus paca, Dasyprocta leporina, Dasyprocta punctata, Hystrix cristata, Myoprocta acouchi, Octodon degus) and semi-aquatic ones (Castor sp., Hydrochoerus hydrochaeris, and Myocastor coypus). The coypu is, however, close to semi-fossorial species based on the astragalus (Fig. 6), this is not completely surprising, since this species is known to dig burrows several meters long. Cursorial taxa are confounded with terrestrial generalists in the astragalus analysis (Fig. 6). For the calcaneus (Fig. 7), however, both groups are quite well discriminated. The semi-aquatic taxa are found between cursorial and generalist taxa in the calcaneus LDA (Fig. 7), but closer to the fossorial/semi-fossorial group in the astragalus LDA (Fig. 6). Due to important differences between astragalus (Fig. 6) and calcaneus (Fig. 7), we treated the two bones separately in the following section.

The LDA allows for easier comparisons of log shape ratios between groups, both visually (Figs. 6 and 7) and by directly calculating the mean of each log shape ratio for each group. These 
559 following section, group means are compared for variables which are significantly correlated 560 with the linear discriminant functions (Table 2A and B). In both the calcaneus and astragalus, 561 MANOVAs showed locomotion and phylogeny had significant effects on the morphology of the 562 bones (Astragalus locomotor category effect: Wilks' lambda $=0.167 ; \mathrm{F}=5.3414 ; \operatorname{Pr}(>\mathrm{F})<$ 563 0.002; Df =1; Astragalus phylogeny effect: Wilks' lambda $=0.0590 ; \mathrm{F}=3.339 ; \operatorname{Pr}(>\mathrm{F})<0.001$; 564 Df $=2$. Calcaneus locomotor category effect: Wilks' lambda $=0.2728 ; \mathrm{F}=2.6661 ; \operatorname{Pr}(>\mathrm{F})<$ 565 0.05; Df = 1; Calcaneus phylogeny effect: Wilks' lambda $=0.0649 ; \mathrm{F}=2.9246 ; \operatorname{Pr}(>\mathrm{F})<0.003$; 566 Df = 2). No significant effects of interactions between phylogeny and locomotion were found. 567 The predictive power of each LDA was tested by leave-one-out cross validation. Both analyses 568 placed about $40 \%$ of the taxa in the right locomotor category (41\% for the astragalus and $36 \%$

569 for the calcaneus) for the extant taxa. It is should be noted that arboreal climbers and cursorial 570 taxa get somewhat better scores with 67\% (astragalus) and 50\% (calcaneus) of right assignations 571 for the climbers, and 43\% (astragalus) and 57\% (calcaneus) for the cursorial. Despite their 572 isolated position in Fig. 6 and 7, no jumping taxa was placed correctly after cross-validation. 573 Fossorial/semi-fossorial taxa, terrestrial generalists and semi-aquatic taxa have less than 40\% 574 correct assignations.

575

576

577

578

579

580

581

582

583

584

585

586

587

588

589

\section{Astragalus (Fig. 6)}

The first two LD axes (shown in Fig. 6) represent $73 \%$ of the variance $(49 \%$ and $24 \%$ respectively). Variables correlated with the linear discriminant functions are shown along the axes in Fig. 6, and the correlation coefficients are presented in Table 2A.

On the first axis, the jumping taxa are discriminated by high MBH and LBH, high SL and low SW values and low Twa, placing them along the negative part of the LD1. Cursorial and generalist taxa occupy the same morphospace, but are separated from semi-aquatic, fossorial/semi-fossorial, and climber taxa. This is linked to higher MBH, LBH and SL values and lower SW and EL values in cursorial and generalist taxa.

The second axis discriminates the semi-aquatic taxa on the negative side of the axis because of high ABW value, low ATL and HH values. Jumping taxa are also discriminated at the opposite side of the LD2, due to low ABW value, high ATL, HH and NL values. Climbers are also on the positive part of the second axis due to their high NL, low ABW, MBH and MTL 
590 values.

591

592

Calcaneus (Fig. 7)

593

The discriminant analysis performed on calcaneal measurements is different from the 595 previous results based on the astragalar variables. With the calcaneus, the LDA does well at separating jumping and climbing taxa from all other categories. The first two discriminant axes (Fig. 7) show $89 \%$ of the variance (74 and 15\% respectively). Variables correlated with the linear discriminant functions are shown along the axes in Fig. 7, and the correlation coefficients are presented in Tab. 2B.

Most groups are separated along the first LD axis, with jumping and cursorial in the negative values on the axis, semi-aquatic and generalist taxa along medium values, and the

602

603

604

605

606

607

608

609

610

611

612

613

614

615

616

617

618

619

620 climber and semi-fossorial/fossorial taxa in the positive values.

High CTL, CAL and CPL values explain the position of cursorial and jumping taxa. Jumpers have the highest $\mathrm{MH}$ value, placing them on the most negative part of the axis. Cusorial and jumping taxa also show low CTW and CCW values. Climbers and fossorial taxa are on the opposite side, characterized by high $\mathrm{CTW}, \mathrm{CCW}$ and $\mathrm{CCH}$ values, combined with low $\mathrm{MH}$, CAL, and CPL values. Semi-aquatic and generalist taxa have medium values, with the semiaquatic group being more on the negative side due to higher CPL, and lower CTW values while the generalists are pulled to the positive side of the axis by a lower CPL and higher CCW and CTW values.

On the second axis the jumping and climbing taxa are discriminated from the rest, due to low NW values for the climbers and high $\mathrm{MH}$ for the jumpers.

\section{A posteriori fossil placement (Figs. 6-8).}

The previous analyses allowed us to define the locomotory categories of fossil taxa. Blainvillimys langei (Theridomyidae) (Fig. 8A) is predicted to be a fossorial species in both the astragalus (posterior probability: 0.99) and calcaneus (0.99) analyses. The position of $B$. langei in Fig. 6 is closer to arboreal climber taxa, however Fig. 6 only represents LD1 and 2, whereas the a posteriori placement is based on all linear discriminant functions taken together. 
622

623

624

625

626

627

628

629

630 631 functions.

632

633

634

635

636

637

638

639

640

641

642

643

644

645

646

647

648

649

650

651 taxa.

\section{Discussion}

astragalus analysis (0.99) and a terrestrial generalist in the calcaneus (0.99) analysis.

Pseudoltinomys gaillardi (Theridomyidae) (Fig. 8C) is found as a fossorial (astragalus

posterior probability: 0.99, calcaneus, 0.99) taxon.

Palaeosciurus goti (Sciuridae) (Fig. 8D) is predicted to be a fossorial species (astragalus posterior probability: 0.99, calcaneus : 0.96).

Eucricetodon atavus (Cricetidae) (Fig. 8E) is, inferred to be a fossorial species from both astragalus and calcaneus analyses (posterior probability: 0.99 and 0.99 respectively). Like $B$. langei, E. atavus is positioned within the climbers group in Fig. 6, again, the a posteriori inference of the locomotory group is different due to the influence of other linear discriminant

Both bones give fairly similar predictions, with some discrepancies in I. pauffiensis. The apparent differences between these predictions and the results of the LDA analyses (Figs. 6 and 7) are due to the fact that the predictions are based on all linear discriminant axes combined, while Figs. 6 and 7 only show LD1 and LD2. The high posterior probabilities found for these fossil species should be taken carefully, as only around $40 \%$ of placements are correct for extant

\section{Functional analysis of locomotor types}

The discriminant variables found in the LDA can be combined with the qualitative characters of the osteological descriptions. In this part we describe the position of the groups, based on the quantitative variables, then combine it with qualitative data, to detect how morphologies converge within locomotor groups.

\section{Quantitative differences between locomotor groups}

Astragalus 
The astragalus body width $(\mathrm{ABW})$ is greatest in semi-aquatic taxa due to the lateral 653 prominence of the ectal facet. It is also high in generalist taxa for the same reason. The high 654 value observed in fossorial/semi-fossorial taxa is linked to the fairly wide trochlea itself, 655 associated with a slight lateral projection of the sustentacular facet. Climbing taxa have a low 656 mean value because their sustentacular facet is not projected laterally. In jumping taxa, the 657 trochlea is compressed transversally explaining the low mean value.

658 The astragalus total length (ATL) is much higher in jumping taxa than in any other 659 category. This is due to an antero-posterior lengthening as well as a transversal compression of 660 all structures of the bone. The lowest value is observed in semi-aquatic taxa, due to the robust 661 morphology of the astragalus.

The astragalus total width (ATW) is highest in generalists due to their wide trochlea, the 663 lateral projection of their ectal facet, as well as a slightly deviated neck. Climbers and 664 fossorial/semi-fossorial taxa also have a fairly high value linked to the medial projection of the 665 neck. The lowest values are found in jumpers, cursors and semi-aquatic taxa, in which the neck 666 is not as much laterally projected. Furthermore, jumping taxa exhibit a transversal compression 667 of the bone.

668 The ectal facet length (EL) shows only slight differences. The highest values are found in 669 climbers, fossorial/semi-fossorial, and generalist taxa. In these taxa, the ectal facet is not 670 projected laterally, but extends medially and antero-posteriorly. Furthermore, it is less curved 671 (and therefore longer), which gives flexibility to the ankle. Jumping and cursorial taxa display 672 the lowest values due to the strong curvature of the facet, limiting the movements of the 673 calcaneus in regard with the astragalus.

674 The head height $(\mathrm{HH})$ is low in cursorial and semi-aquatic taxa, mainly due to the overall 675 reduction in size of the head. Functionally, this could imply less flexibility. Highest values are 676 found in jumping taxa in which the shape of the head allows for a wide array of parasagittal 677 movements of the foot.

678 The head width (HW) is quite similar in all categories. Fossorial/semi-fossorial and 679 cursorial taxa have the widest astragalar head, enabling some flexibility to the foot independently 680 of the ankle, since the head of the astragalus articulates anteriorly with the navicular. At the other 681 end, semi-aquatic taxa have the narrowest head, greatly limiting transversal movements of the 682 foot independently of the ankle. 

and fossorial taxa, due to a flatter shape of the trochlea in medial and lateral views. This trochlear shape is, in turn, linked to a lesser arc of parasagittal movements in these taxa. Conversely, jumping and cursorial taxa have highest lateral and medial body height, due to a greater curvature of the trochlea, which relates to a wide arc of parasagittal movement.

The lateral trochlear length (LTL) is very similar in all categories, except for the semiaquatic taxa, for which it is shorter. Again, this is due to a short and more symmetrical astragalus in these taxa. The medial trochlear length (MTL) is smallest in climbers and fossorial/semifossorial taxa, where a marked asymmetry is noticeable between the lateral and medial parts of

692 the trochlea (i.e., LTL and MTL are markedly different). This asymmetry adds a transverse component to the plantar and dorsiflexion of the foot. Jumping and generalist taxa also show a medium asymmetry, while cursorial and semi-aquatic taxa have an almost perfect symmetry of the trochlea. The reduction of the asymmetry means the foot will stay on the parasagittal plane during plantar or dorsiflexion of the foot, allowing for more efficient ruuning/paddling.

The neck length (NL) is highest in jumping taxa, in which the neck is lengthened anteroposteriorly. The neck is also long in fossorial and arboreal climber taxa, in part because it is deviated medially. This gives a greater flexibility to the foot, either in the parasagittal plane (for jumping taxa) or medially (for fossorial/climber taxa). Other taxa have a shortened neck, suggesting less flexibility of the foot in regard with the ankle.

The sustentacular length (SL) is higher in jumping, cursorial and semi-aquatic taxa, where it favours parasagittal movements. In fossorial taxa, the antero-posterior dimension of the sustentacular facet is generally reduced, limiting antero-posterior mobility of the astragalus in regard to the calcaneus. Indeed, in fossorial taxa, these bones should be maintained together during parasagittal movements (e.g., pushing back the soil).

The sustentacular width (SW) is highest in fossorial and climber taxa. The transversely oriented shape of the sustentacular facet permits medio-lateral movements, crucial for these locomotor categories. In jumping and cursorial taxa, the facet is transversely compressed (i.e., SW is small), again in accordance with the nature of the movements of the foot, which are mainly parasagittal. 
714 value and are characterized by asymmetrical and slightly divergent medial and lateral parts of the

715 trochlea. The widest trochlea is found in semi-aquatic taxa, in which the astragalus is shortened

716 and widened. Fossorial/semi-fossorial taxa also have a fairly wide trochlea, bringing some

717 stability to the upper ankle joint.

718

719

\section{Calcaneus}

720

The calcaneus anterior length (CAL) is highest in jumping and cursorial, it is intermediate

721

722

723

724

725

726

727

728

729

730

731

732

733

734

735

736

737

738

739

740

741

742

744

743 EW is highest in cursorial and semi-aquatic taxa, and lowest in jumping, fossorial/semi-

in generalist taxa, and the lowest values are found in fossorial, arboreal climbers and semiaquatic taxa. Morphologically, this means that the body of the calcaneus, situated anteriorly to the ectal facet, is lengthened in terrestrial taxa, especially specialized cursorial and jumpers taxa, while it is shortened in taxa specialized in other substrates.

The posterior length (CPL) is highest in cursorial and semi-aquatic taxa. It is also high in jumping taxa, while generalists, as well as climbers, show lower values. The lowest mean value is found in fossorial/semi-fossorial species.

The calcaneo-cuboid height $(\mathrm{CCH})$ and the calcaneo-cuboid width $(\mathrm{CCW})$ define the shape of the calcaneo-cuboid facet. In general, its shape differs in anterior view. This facet is biggest (i.e. $\mathrm{CCH}$ and $\mathrm{CCW}$ have the highest values) in fossorial/semi-fossorial and arboreal climber taxa. In these species, it has an elliptical shape, whereas it is more slender in other categories, with a dorso-plantar main axis, and a transverse compression. This elliptical shape of the facet allows a variety of movements of the foot, through the cuboid, in fossorial/semifossorial and climber taxa. In other taxa, transverse movements of the foot are generally more limited, due to a narrower facet (i.e. CCW has lower values in terrestrial and semi-aquatic taxa).

The calcaneal ectal length (EL) measurements can differ from those of the ectal facet of the astragalus. The jumping and semi-aquatic taxa display low values (same as the astragalus) due to the much curved shape, and the perpendicular orientation of the facet in dorsal view. Conversely, in climbers and generalists taxa, the calcaneal ectal facet is less curved, mainly oriented antero-posteriorly, and posteriorly lengthened to increase mobility between the two bones. Fossorial taxa show a low value, whereas they showed a high value for the astragalar ectal facet. fossorial and generalist taxa. Climbers show intermediate mean value. This variation does not 
745 match that of the astragalar ectal facet. On the calcaneus, EW is only correlated with LD4 and

746 LD5, and on the astragalus it is not correlated with any linear discriminant axis. It seems that the

747 EW does not display a strong ecomoprhological signal.

748 The maximal height $(\mathrm{MH})$ of the calcaneus is highest in jumping taxa. It is also

749 intermediate in cursorial, generalist and semi-aquatic taxa. Lower values are found in

750 fossorial/semi-fossorial and climbers taxa. The variation in $\mathrm{MH}$ is linked mainly to the

751 orientation and projection of the ectal facet (see Fig. 2). The high values found in jumping,

752 cursorial, generalist and semi-aquatic taxa are therefore linked to their ectal facet being oriented

753 perpendicularly to the antero-posterior axis of the bone.

754 The neck width (NW) is lowest in climbers taxa. This is linked to the curvature of the

755 neck and the "pinch" that is visible at the middle of the neck in these species (e.g. Fig. 3D).

756 Cursorial taxa show an intermediate value, while other categories have higher value, explained

757 by a more robust neck shape.

758 The calcaneal sustentacular length (SL) is reduced in cursorial, fossorial and generalist

759 taxa, where the shape of the facet does not facilitate antero-posterior movements of the calcaneus

760 with regard to the astragalus. Conversely, the SL in jumping, semi-aquatic, but also climbing

761 taxa is high, meaning that the bones have a relative independence in antero-posterior movements

762 in these taxa.

763 The sustentacular width (SW) is low in taxa that mainly use parasagittal movements (i.e.

764 mainly jumping and cursorial but also semi-aquatic). Fossorial, climbers and generalists taxa, in

765 which the ankle is more mobile transversely, show higher values.

766 The tuber height (TH) is greatest in fossorial and climber taxa. Generalists display an

767 intermediate value, while jumping, cursorial and semi-aquatic taxa have lower average TH. The

768 shape of this area is linked with the insertion of the Achilles tendon.

769 Jumping and fossorial/semi-fossorial taxa have the highest TWc values, while generalists,

770 semi-aquatic and cursorial taxa have intermediate values. All these taxa show a rather robust

771 tuber morphology. Conversely, arboreal climbers have a very low TW value, linked to a more

772 slender tuber.

773

774

\section{Morphology and function in the locomotor groups}



parasgittal movements). However, they also show differences, which are clearly underlined in the discriminant analyses and will also be surveyed.

782

Astragalus. In these taxa, the trochlea of the astragalus is almost symmetrical, with rims aligned in the parasagittal plane. The trochlea is also transversally compressed (low TW value, especially in jumping taxa). In this context, the foot moves in the parasagittal plane when rotated (Carrano, 1997; Candela and Picasso, 2008). The trochlear groove is deeper, and both sides of the trochlea are steeper than in other taxa. This restricts or may even suppress any transverse movement when the foot is dorsally or plantarly flexed (Carrano, 1997; Candela and Picasso, 2008). In these taxa, limited transverse movements may be of major importance to avoid injuries at the ankle (Hildebrand 1985a ; Hildebrand and Goslow 2001). The astragalar neck is of variable lengths, longer in jumping taxa (high NL value), in which it participates to the great lengthening of the foot seen for example in gerboas. It is shorter in cursors, which have a low average NL value. In both groups the neck is barely or not deflected medially. As a consequence, the sustentacular facet (of variable length, depending on the neck) is always anteroposteriorly oriented. This greatly reduces the transverse movements of the calcaneus below the astragalus (Candela and Picasso, 2008), making the inversion of the foot impossible or extremely difficult. In addition, the sustentacular and ectal facets are usually separated by a deep and/or wide sulcus, which suggests the presence of strong ligaments between the two bones (Fig. 1A and 1B) that make them less independent in their respective motions (conversely to what is seen in flying squirrels, see P. volans ; Thorington et al., 2005). The deep sulcus and antero-posterior sustentacular facet are, again, diplays of the great resistance of the ankle necessary in these two types of locomotion (Hildebrand 1985a ; Hildebrand and Goslow 2001). The ectal facet of the astragalus is generally strongly projected laterally, and its calcaneal counterpart matches perfectly with it. This limits the transverse and anteroposterior mobilities of one bone with regard to the other. In these taxa, the astragalus and calcaneus are more tightly linked than in 
807 the navicular is different in cursorial and jumping taxa. The former have a very low $\mathrm{HH}$ value 808 and rather high HW, while the latter have high $\mathrm{HH}$ and intermediate HW. In functional terms, 809 this suggests that the anterior part of the foot in jumping taxa has more mobility in regard with 810 the ankle than in cursorial taxa. This may allow jumping taxa to gain some elastic force when 811 landing, and/or to cope with stresses produced on the lengthened metatarsals (injury avoidance ; 812 Hildebrand 1985a; Hildebrand and Goslow 2001). One final characteristic element is the AmT

813 facet, which can be of variable length, but is barely or not visible on the neck in dorsal view. It is 814 actually developed on the medial and plantar sides of the neck. Therefore, the medial tarsal is 815 positioned plantar to the astragalus, providing resistance against the reaction forces (directed 816 upwards) transmitted to the ankle during locomotion (Hildebrand 1985a ; Hildebrand and 817 Goslow 2001).

818 Calcaneus. The calcaneal ectal facet is usually shorter in jumping than in cursorial taxa 820 (lowest EL value for jumping taxa)but its anterior part is always oriented perpendicularly to the 821 dorsal surface of the body of the bone and corresponds to the strong curvature of the ectal facet 822 of the astragalus (low astragalar EL in both groups). As a whole, the shape of the calcaneus is 823 straight and aligned in the parasagittal plane. The neck is straight and of regular width. The body 824 is usually long and rather narrow (lowest CTW values in jumping and cursorial taxa) in 825 comparison with other taxa. This shape shows that transverse movements are probably very 826 infrequent and favors parasagittal motions instead. The calcaneo-cuboid facet is oblique in dorsal 827 view, crescent or bean-shaped, and a dorso-plantar main axis. Such a shape implies again that the 828 cuboid has limited transverse movements with respect to the calcaneus (Candela and Picasso, 829 2008). The morphology of the facet seems to be convergent with other cursorial mammals such 830 as some artiodactyls (e.g., Bovinae and Caprinae, pers. obs.). The peroneal process is reduced or 831 absent, therefore changing the lever system of the peroneus muscle group into a direct pulling 832 (with no fulcrum, see Fig. 1 and Supp. material 1). This should greatly reduce the possibility of 833 abducting and/or everting the foot, contrary to climber taxa.

834

835 Terrestrial generalists

836 837 Calcaneus. Overall, it has a robust shape, not displaying marked lengthening 
838 (intermediate CAL and CPL values). The peroneal process is sligthly developped laterally 839 (contrary to cursors/jumpers where it is absent), and in an anterior position (unlike 840 climbers/fossorial taxa where it is more posterior). One exception is C. porcellus (Fig. 5K) where

841 the process is absent, similar to cursorial and jumping taxa. Ectal and sustentacular facets are not 842 much developped (low average SL and EW and intermediate EL values). Both facets are always 843 separated by a sulcus, except for Ctenodactylus vali (Fig. 5J) where they form a continuous 844 articular surface. The calcaneo-cuboid facet is developped and with a wide crescent shape, with a $845 \mathrm{CCW}$ average value intermediate between cursorial/jumping taxa and fossorial/climber taxa. In 846 C. porcelus, it is smaller than in other generalists (Fig. 5K). The neck is straight and robust in all 847 generalist taxa.

848

Astragalus. The ectal facet is not projected laterally (except in $O$. degu and P. cuvieri,

851 C. vali, corresponding to what is seen in the calcaneus (Fig. 1A and B). The head is projected 852 laterally and developped with a rather round shape, except in C. porcellus, where it is less 853 developped in width and length (Fig. 5K). The astragalo-navicular facet is developped on the 854 dorsal side of the neck, as well as AmT facet. The sustentacular facet has an ovoid shape 855 (intermediate SL and SW values) and does not join with the AN facet, except in C. porcellus 856 where it is extended and joins anteriorly with the AN facet. The trochlea is rather symmetrical 857 (high LTL and MTL average values), with an deep groove. It appears to be more asymetrical in $858 O . \operatorname{deg} u$ than in other generalist taxa

Overall the generalists display characters suggesting a rather good flexibility at the ankle.

860 It should be noted that Cavia porcellus shows some cursorial characterisitcs (lengthened 861 astragalar sustentacular facet, absence of peroneal process), and that Octodon degu seems to 862 have more flexibility than other, with some characters similar to climbers (continuous ectal and 863 sustentacular facets, asymmetrical trochlea). It is also important to note that all generalist taxa 864 studied here are members of the Ctenohystrica, which may also influence the similarities in 865 morphology. However, members of the Ctenohystrica which are not generalists display different 866 morphologies, suggesting that the qualitative characters described before are not influenced 867 solely by phylogenetic proximity. 
870

Calcaneus. The calcaneus of climber taxa shows common features. The medial curvature

872 of the neck may be linked to the direction of the forces that are strongest and most often exerted

873 (i.e., during inversion and plantar flexion of the foot) by the muscles on the tuber (gastrocnemius 874 and soleus, see Supp. Material Tab. 1). Indeed, each time the calcaneus pivots medially, its 875 medial side anatomically moves to a more dorsal position. Therefore, the muscle stresses are not 876 exerted on the dorsal side of the neck but on its medial side, which is in a dorsal position (Supp. 877 material, Tab. 1 and below). During this movement, the bending of the neck of the calcaneus 878 may provide a stronger resistance to the large forces applied, or may be due to the fact these 879 stresses were present during the growth of the bone and influenced its shaping. Interestingly, some arboreal marsupials display a similar character state (such as Caluromys philander in: Szalay, 2006, p.193, Figs.7.8). The importance of the stress produced by the gastrocnemius

882

883

884

885

886

887

888

889

890

891

892

893

894

895

896

897

898

899 muscle may explain the high value of trochlear height (TH) found in climbers. Indeed, the TH is influenced by the development of the Achilles tendon insertion area (Fig. 1). In climbers, this insertion is probably strenghtened in order to sustain the stress induced during inversion. The peroneal process is well-developed in all climber taxa studied; it is also in a posterior position on the lateral side of the bone (Emry and Thorington, 1982 ; Thorington et al., 2005, Fig. 10 ; Rose and Chinnery, 2004; Candela and Picasso, 2008). The process forms a fulcrum for the tendons of M. peroneus longus and brevis, abductors/eversors of the foot (Fig. 1, Supp. material Tab. 1). A wide and posterior peroneal process may therefore improve the mobility of the foot by facilitating its eversion and/or abduction through a change in the characteristics of the lever system of the peroneus muscles. In that case, the lever system is a "type 3 lever", where the effort is exerted between the fulcrum and the resistance (Davidovits, 2012). Therefore, the posterior position of the peroneal process increases the in-lever length, producing a greater mechanical advantage for the peroneus muscles. It should also increase the resistance to forces on the opposite (medial) side during inversion. The shape and orientation of the calcaneo-cuboid facet (slightly concave, circular, and oriented transversely or only slightly oblique) also allows for a great variety of movements at the level of the cuboid bone (Candela and Picasso, 2008). The circular shape of this facet in climbing taxa explains the high $\mathrm{CCW}$ and $\mathrm{CCH}$ values found in that group. This last character state, associated with the shape of the talar head, gives a great 
900 deal of flexibility to the transverse tarsal articulation, and consequently makes the distal part of

901 the foot more independent from the ankle (Candela and Picasso, 2008). In climbers, this

902 flexibility is probably needed to cope with the varying slope and irregularities of the substrate.

903

904

Astragalus. The trochlea of the astragalus of frequent climbers is generally very

905

asymmetrical. As such, the rotation axis of the foot is not parasagittal but has a transverse

906 component (Szalay, 1985; Candela and Picasso, 2008). The foot can therefore adapt to substrates

907 of variable inclination, usually by different degrees of inversion/eversion positions (Szalay, 1985; Carrano, 1997; Candela and Picasso, 2008; Schmidt and Fischer, 2011). Furthermore, the trochlear groove is shallow, and both the lateral and medial parts are generally not steep towards it. P. volans shows a sharper groove than S. vulgaris. This character was described in flying

911 squirrels as a more "V"-shaped trochlea by Thorington et al. (2005) (however, we would

912 describe it as a more "checkmark"-shaped trochlea, considering the asymmetry of the lateral and

913 medial sides). This allows the upper ankle joint (UAJ) to have some lateral mobility, even when

914 the foot is dorsally or plantarly flexed (Szalay, 1985). The neck of the astragalus may be long,

915 but it seems that a strong medial deviation might best characterize climbing rodents. Indeed, all

916 climber taxa studied qualitatively here (Sciurus, Pteromys, and Coendou) have a medially

917 deflected neck, but only the squirrels have a particularly long neck. An elongated and/or

918 deflected neck increases the articular surface of the plantar sustentacular facet, along which the

919 calcaneus may slide. Furthermore, the orientation of the facet, following the axis of the neck,

920 favours medial movements, which are particularly required to invert the foot position (Szalay,

921 1985; Candela and Picasso, 2008). In relation with the previous points, the broadening of the

922 ectal and sustentacular facets, or their confluence, creates a more continuous surface of

923 articulation and reduces the attachment of ligaments (notably with the disappearance of the

924 sulcus in $P$. volans). The absence of a sulcus between the facets in flying squirrels has also been

925 noted by Thorington et al. (2005), who linked it to the extremely inverted position of the foot

926 during gliding. In any case,the combination of morphological features found in all climbing

927 rodents studied here facilitates any potential movements of the calcaneus along the articular

928 surfaces of the astragalus. This, in turn, allows the foot to move more independently with respect

929 to the leg, thanks to a flexible ankle (Szalay, 1985; Candela and Picasso, 2008). The AmT facet

930 is developed on the dorsal and medial aspects of the astragalar neck. Therefore, when important 
931 constraints are applied to the medial side of the astragalus (i.e., during inversion of the foot while

932 climbing), the medial tarsal bone can support the astragalus by taking a more medial or dorsal

933 position, thereby stabilizing the ankle (Emry and Thorington, 1982; Szalay, 1985; Candela and

934 Picasso, 2008). The proximo-plantar edge of the trochlea ends in a salient medial tuberosity,

935 which will stop the medial side of the neck of the calcaneus in a maximal foot inversion

936 (although separated by different layers of non-osseous tissue). This character also maintains and

937 stabilizes the ankle joint during inversion of the foot. Finally, the wide, sometimes rounded

938 astragalar head, together with the confluence of its articular facets, show that the distal tarsal

939 bones articulating with it (navicular and medial tarsal) may take various positions with regard to

940 the astragalus. This mobility of the distal tarsals translates in a great flexibility of the distal part

941 of the foot, again required by the use of irregular and inclined substrates (Szalay, 1985; Candela

942 and Picasso, 2008).

943

944

Fossorial taxa

945

946

The semi-fossorial ground squirrels (Marmota and Spermophilus) show an interesting combination of traits similar to arboreal sciurids (e.g., a strong peroneal process, a long and deflected astragalar neck, an asymmetrical trochlea), however with some notable differences : the trochlea is not as asymmetrical as in arboreal climbing squirrels, and the peroneal process, although well developped is in a more anterior position (Emry and Thorington, 1982). These characters could be ancestral to the group since some of the earliest sciuroids were probable climbers (e.g., Douglassciurus Douglas, 1901; Emry and Thorington, 1982 ; Vianey-Liaud et al. 2013). The more anterior position of the peroneal process, the deep sulcus between the ectal and sustentacular facets, the astragalar sustentacular facet less medially developed, or the short calcaneal body in comparison to the calcaneal neck, characterize terrestrial rather than arboreal forms (Szalay, 1985; Carrano, 1997; Candela and Picasso, 2008 ; Thorington et al., 2005).

In Spalax (the only fully subterranean species studied here), the calcaneo-astragalar complex combines a good mobility at the ankle, characterized by a wide trochlea with a shallow groove, long astragalar neck with a spherical head, long calcaneal ectal facet, developed peroneal process; with a powerful plantar stroke, thanks to the elongation of the in-lever arm that produces 
962 calcaneal body; Carrano, 1997; Davidovits, 2012). This is likely to help maintain the animal

963 while digging and/or to push the dirt out of the way (Hildebrand, 1985b).

964 The peroneal process is developed in Spalax, as well as in semi-fossorial species

965 (Marmota Marmota, Spermophilus fulvus, and Microtus gregalis). Therefore, the eversion and 966 abduction of the foot are probably important elements in fossorial behaviours, as well as in 967 arboreal climbing, although they do not serve the same purpose. In semi-fossorial species, the 968 neck of the calcaneus bears well-marked muscular insertion areas, especially in Marmota. Like 969 in Spalax, this is certainly linked to the power of the lever arm of the foot, crucial in digging, 970 even though M. marmota, S. fulvus and M. gregalis cannot be considered as complete fossorial 971 species. The calcaneal ectal facet is not lengthened in fossorial taxa (low EL value), and neither 972 is the sustentacular facet (low SL value for the astragalus and calcaneus). Indeed, the astragalus 973 and calcaneus should be maintained together under important constraints, rather than be allowed

974 to move independently. In fossorial and semi-fossorial taxa, the flexibility of the ankle mainly 975 depends on the UAJ, as well as the astragalo-navicular joint (high HW value with a developped 976 and convex AN facet).

977 It is interesting to note that the peroneal process length (PPL) is highest in fossorial 978 species. The development of this process is linked to the passage of the tendons of the peroneus 979 muscle group (Fig. 1), which are responsible for the eversion of the foot. The importance of the 980 peroneal process in fossorial taxa may be explained by the movements used to push back the soil 981 while digging (possibly a partially lateral movement, rather than just a backwards parasagittal 982 movement). The peroneal process is also present and developped in climber taxa (second highest 983 PPL average score), in which eversion is frequent during climbing. It appears the less a taxon is 984 using transversal movements of the foot, the more reduced its peroneal process is (e.g., semi985 aquatic and jumping taxa have the lowest PPL values).

986

987

Semi-aquatic

988

Although the castor and coypu have different morphologies for their astragalus and 990 calcaneus, probably due to their distant phylogenetic relationship, we can identify several 991 convergent character states.

Calcaneus. The calcaneus of both species bears an ectal facet that is oriented towards the 
993 medial side. This may be linked to an increase in the parasagittal arc that the foot may produce

994 when swimming, therefore improving the hindlimb propulsion. In both species, the sustentacular

995 facet is concave, which may improve the stability of the astragalus on the calcaneus during

996 movements. Finally, both species display a very deep and wide groove for the flexor fiblaris

997 muscle (Fig. 1A). This muscle plays a role in parasagittal movements of the foot (Supp. Material

998 Tab. 1), especially plantar flexion, which is important when paddling. The importance of the

999 groove for the tendon of this muscle suggests that the muscle is very active in semi-aquatic 1000 species.

1001

1002

Astragalus. The astragalus facets appear very similar. Indeed, the ectal facet is wide

1003 (highest EW mean value), mirroring that of the calcaneus, and suggesting that the ankle may

1004 have some flexibility in semi-aquatic species. If fhe sustentacular facets have very different

1005 shapes, they are both mainly oriented antero-posteriorly (highest mean SL value), as in other taxa

1006 where dominant movements of the foot are parasagittal. Finally, the neck shows slight deviation

1007 towards the medial side in both species, suggesting again that there may be moderate flexibility

1008 in the ankle of semi-aquatic taxa.

1009

1010

1011 Proportions of the calcaneus as the lever arm of the foot.

1012

1013

Since the calcaneus can be seen as a lever (Carrano 1997; Davidovits 2012), the

1014 functional significance of the CAL and CPL values appears more clearly through a ratio of in-

1015 lever/out-lever proportions. If $\mathrm{F}$ is the force necessary to move the foot, CAL can be considered

1016 as the out-lever, CPL as the in-lever, and $\mathrm{k}$ as the resistance force of the substrate (Davidovits

1017 2012). Therefore, we have $\mathrm{F}=(\mathrm{CAL} / \mathrm{CPL})+\mathrm{k}$. Using logshape ratios values for $\mathrm{CAL} / \mathrm{CPL}$, the

1018 results are as follows : jumping, 1.06 ; cursorial, 0.69 ; generalist, 0.88 ; fossorial, 0.40 ; climber,

10190.45 ; semi-aquatic, 0.24 .

1020 The ratio is lower in fossorial, climber and semi-aquatic taxa. Such ratios enable these

1021 taxa to compensate for greater resistance forces $(\mathrm{k})$. For climbing taxa, $\mathrm{k}$ may be increased by the

1022 effects of gravity. In fossorial taxa, pushing back the soil would be the main resistance force

1023 applying, however, the CAL/CPL value observed is not as low as in semi-aquatic taxa. This may 
1024 be explained by the fact that the hindlimbs are used to brace the animal (Hildebrand 1985b) and

1025 push out the soil during digging, rather than to do digging itself. In semiaquatic taxa, water

1026 resistance could be one element to account for increasing k. However, the taxa studied here are

1027 quite often burrow diggers, and this behaviour could also partly explain the $\mathrm{k}$ value observed

1028 here. Interestingly, the coypu does not group with the castor and capybara in Figs. 6 and 7. This

1029 may be due to the smaller size of the former, creating less drag when swimming, and therefore

1030 requiring less morphological specialization to overcome it.

1031

1032 LDA interpretation caveats

1033

1034

The LDAs allow us to determine which variables show inter-group variance (i.e. between locomotor categories). Since these variables are significantly correlated with locomotory categories, they can be used to infer the locomotory group of a specimen with some certainty. However, the Wilks lambda values are rather high, and cross validations are not very successful, which suggest that the predictions should be taken with caution. Still, the morphology shows locomotory signal, and we can be fairly confident in our inferrences, notably for for the cursorial and climber taxa.

The differences in the group discriminations observed between astragalus and calcaneus can be explained functionally. Indeed, although these bones are part of the same complex unit

1043 (the ankle), they have quite different functions. The astragalus is a pivot, the fulcrum of the foot 1044 as a lever (Carrano 1997, Davidovits 2012); it must ease or limit movements, depending on the 1045 favoured mode of locomotion. On the other hand, the calcaneus is part of the active movement; it 1046 is the lever arm (Carrano 1997, Davidovits 2012) that transmits the energy from muscular effort. 1047 In other words the calcaneus applies forces, whereas the astragalus only guides the movements. 1048 For instance, the astragalus of fossorial rodents is show some similarities with that of arboreal

1049 climber taxa, probably because they both need to have ankles that show some sort of flexibility 1050 (for climbing in arboreal taxa, or for pushing soil and maneuvering in tunnels for fossorial taxa). 1051 We should therefore use caution when making interpretations based on an isolated bone. 1052

1053 Inference of locomotion in fossil rodents (Figs. 6-8) 
1055 Discrepancies between inferences from astragalus and calcaneus are present in one case

1056 (Issiodoromys pauffiensis). It is one of the reasons why a posteriori placement in a LDA should

1057 be used with caution when inferring the locomotor group of a fossil species, especially when

1058 only one bone is available. Of course the low success of cross validation is the main problem

1059 with these inferrences. Still, discrepencies within taxa, between bones are not surprising and can

1060 be explained by the different roles that each bone of interest can play during movements (see

1061 preceding paragraph). Fossorial and generalist taxa may be further confounded by the fact that

1062 terrestrial generalists may also be burrow diggers (e.g. Spermophilus fulvus, Tsytsulina et al.

1063 2008; Octodon degus, Woods and Boraker 1975).

1064 Regarding Palaeosciurus goti, the result is in accordance with Vianey-Liaud (1974),

1065 which described it as a "terrestrial squirrel", rather than an arboreal climber. The astragalus,

1066 when taken as the fulcrum of the foot-lever (Carrano 1997, Davidovits 2012), displays the

1067 flexibility required in the digging process (Figs. 8-B3 and 8-B4, right). The calcaneus also

1068 matches with that of fossorial/semi-fossorial taxa. Since all terrestrial squirrels studied here are

1069 also semi-fossorial, it is fairly plausible that $P$. goti had a similar ecology and locomotion.

1070 Vianey-Liaud et al. (2015) defined the lifestyle of $P$. goti as scansorial/terrestrial (Vianey-Liaud

1071 et al. 2015 Supp. data, Tab. 10.6) and proposed that P. goti would have been an occasional

1072 climber. The result presented here does not exclude this possibility since some of the terrestrial

1073 generalists taxa studied are also occasional climbers (e.g. Ctenodactylus vali, Fig. 5J Gouat

1074 1987; O. degus, Fig. 5O, Woods and Boraker 1975). Furthermore, the astragalus presents a

1075 morphology allowing flexible movements of the ankle, which may have been of use either for

1076 digging or climbing (climbers and diggers are close in Fig. 6 because of some similar functional

1077 constraints). However, although occasional climbing may have been possible in $P$. goti, the

1078 qualitative characters seem in accordance with a semi-fossorial lifestyle. When comparing with

1079 other fossil and extant squirrels (Emry and Thorington 1982, Korth and Samuels 2015), it

1080 appears that the calcaneus of Palaeosciurus has a shorter and wider neck than Douglassciurus

1081 (Emry and Thorington 1982) or Protosciurus (Korth and Samuels 2015). The neck is only

1082 slightly deflected medially, and the medial part of the tuber is more prominent than the lateral

1083 part, similar to Protosciurus (Korth and Samuels 2015). The ectal facet has a shape closer to that

1084 of Protosciurus (described as "trapezoidal" in Korth and Samuels 2015) than to Douglassciurus

1085 or Sciurus. The sustentacular facet is round and separated from the ectal facet by a deep groove 
1086 like in Protosciurus and Douglassciurus. The peroneal process is most similar to that of

1087 Spermophilus beecheyi (Emry and Thorington 1982), well-developped laterally, and in a rather

1088 anterior position. Overall, the calcaneus of Paleosciurus shows a few similarities with

1089 Protosciurus (ectal facet shape, tuber shape) which is considered to be arboreal according to

1090 Korth and Samuels (2015). However, the more anterior peroneal process as well as the shorter

1091 and wider neck of $P$. goti show a more terrestrial lifestyle, in accordance with Vianey-Liaud

1092 (1974), and our quantitative analysis suggests $P$. goti was also burrow-digging.

1093 Issiodoromys pauffiensis is placed among the terrestrial generalists in the calcaneus

1094 analysis, and among the arboreal climbers in the astragalus analysis. This result is in

1095 disagreement with the findings of Vianey-Liaud et al. (2015), which proposed that the species of

1096 the genus were jumping. However, it should be noted that no extant jumping taxa was correctly

1097 placed in the cross validated LDAs, which may explain the incoherence between those results.

1098 Qualitatively, the calcaneal and astragalar morphology of I. pauffiensis (Figs. 8-B1 to B4; see

1099 also Vianey-Liaud et al. 2015, Fig. 20.11) may be in accordance with a cursorial or jumping

1100 locomotion. The calcaneus is long, with a slender anterior part (Fig. 8-B3). The peroneal process

1101 is in a distal-most position, and not very prominent, and the base of the ectal facet is

1102 perpendicular to the main axis of the bone (visible in lateral view). However, the calcaneo-

1103 cuboid facet has a unique shape (Fig. 8B4). Some qualitative characters of the astragalus of $I$.

1104 pauffiensis may explain why it is found in the climbing taxa. Indeed, the astragalar neck is long,

1105 and the trochlea is rather asymmetrical, similar to some extant climber taxa. However, the

1106 lengthening of the sustentacular facet, which joins distally with the AN facet, as well as the

1107 shape and curvature of the ectal facet are closer to that of cursorial and jumping taxa (e.g. Fig. 9).

1108 Other skeletal elements presented in Vianey-Liaud et al. (2015), are also in accordance with a

1109 jumping locomotion.

1110 Vianey-Liaud et al. (2015) described the forelimb of Pseudoltinomys gaillardi, but were

1111 not able to make inferences about its locomotor repertoire. Our results (P. gaillardi is inferred as

1112 a fossorial species) disagree with the hypothesis of a "parallel adaptation of [the Pseudoltinomys]

1113 genus alongside that of Issiodoromys" (Vianey-Liaud et al. 2015, Discussion and conclusion),

1114 since Issiodoromys comprises cursorial and jumping species rather than fossorial ones (see

1115 Results, Figs. 6 and 7; Vianey-Liaud et al. 2015, Discussion and conclusion). The known 1116 elements of the forelimb (described in Vianey-Liaud et al. 2015) do not exclude a fossorial or 
1117 semi-fossorial lifestyle in this species. Using an "index of fossorial ability" (Lagaria and 1118 Youlatos 2006), with the values given in Vianey-Liaud et al. 2015 (Pseudoltinomys gaillardi,

1119 Forelimb) the result found is $3.96 /(23.42-3.96)=0,203$. This value is similar to that of other 1120 extant fossorial taxa (Lagaria and Youlatos 2006). Comparing with the values of the OLI index 1121 presented in Samuels and Van Valkenburgh (2008), P. gaillardi is found to be in the range of 1122 semi-fossorial or semi-aquatic taxa. Those elements support our own result of a semi-fossorial 1123 lifestyle for P. gaillardi.

1124 Blainvillimys langei and Eucricetodon atavus are both close to the fossorial group. $B$. 1125 langei was considered as a cursorial species by Vianey-Liaud et al. (2015). However, looking 1126 qualitatively at the morphology of the calcaneus and astragalus (Fig. 8-A; see also Vianey-Liaud 1127 et al. 2015, Fig 20.5), it does resemble other fossorial/semi-fossorial species. Indeed, the 1128 astragalar sustentacular facet is reduced and does not join the AN facet, whereas it usually is 1129 elongated antero-posteriorly in cursorial taxa (and in some species joins the AN facet, see 1130 Discussion, jumping and cursorial taxa; Fig. 9). Furthermore, the astragalar head is somewhat 1131 rounded, and the neck is long and slightly deflected medially, similar to other fossorial taxa (see 1132 Discussion - In other taxa, Fig. 3A and 4H for examples). The calcaneus (Fig. 8-A3 and 8-A4, 1133 left) shows a wide (rather than elongated) anterior part, with a developed peroneal process, but in 1134 a more posterior position than in cursorial or jumping taxa (see Discussion, jumping and 1135 cursorial taxa; Fig. 9).

1136 It should be acknowledged that inferences based on the calcaneus seem more easily 1137 interpretable than the ones made on the astragalus, mainly because fossil specimens fall close or 1138 within the range of extant functional groups. The fact that the linear proportions of the calcaneus 1139 reflect its function could partly explain this result, whereas for the astragalus, the function may 1140 also be reflected by non-linear measurements such as the angle of the neck, the "roundedness" of 1141 the head, or the asymmetry of the trochlea. However, it can also be explained by the sampling of 1142 extant taxa, which is probably not representative of the full morphological diversity of extant 1143 rodents, nor representative of fossil morphological diversity.

\section{Conclusions}


1148 rodents are generally very versatile in this regard, we showed that the bones of the ankle are 1149 good indicators of their main locomotor mode, particularly in specialized taxa (e.g., arboreal 1150 climbers, fossorial or jumping forms). This relation can be used, to some extent, to infer 1151 locomotor behaviours in fossil taxa. The astragalus and calcaneus are of particular interest in this 1152 regard, since they are often found in the fossil record. We showed that hypotheses can be made 1153 even based on isolated astragalus or calcaneus (e.g., Candela and Picasso, 2008; Vianey-Liaud et 1154 al., 2015) in concert with other quantitative and/or qualitatitve analyses (Samuels and Van 1155 Valkenburgh, 2008; Bover et al., 2010). This type of approach has already been applied 1156 successfully in primates (e.g., Dagosto, 1986, 1988, 1993; Gebo and Simons, 1987; Gebo, 1988;

1157 Gebo et al., 2001; Marivaux et al., 2010, 2012). Although quantitative analyses have the 1158 potential to make inferences based on a large dataset, the results of this study suggest that these 1159 inferences should be made carefully, and with the largest possible sample size. Comparative 1160 anatomy, if possible accompanied by some functional interpretations, should still be used as a 1161 referential (rather than directly interpreting quantitative analyses), or as a mean to compensate 1162 for lack of morphological representativeness of the extant dataset.

1163 Some important caveats are to be acknowledged when making inferences with this 1164 approach. First, since the shape of the bones does not respond to locomotion itself, but to the 1165 constraints that are applied to the bones, convergent morphologies may well occur between 1166 different types of locomotion that use similar movements. For instance, bipedal versus 1167 quadrupedal jumping would be hardly discernible among jumping species based on their 1168 astragalus and/or calcaneus solely. Similarly, semi-aquatic and cursorial taxa are hard to 1169 discriminate qualitatively or quantitatively because both groups use parasagittal movements of 1170 the foot to swim and/or run. Phylogenetic bias should also be taken into account, especially when 1171 phylogenetic groups are confounded with locomotor categories (e.g., in our case, most climber 1172 taxa are also sciurids). One should also be careful when using these "functional categories" 1173 (Elissamburu and Vizcaino, 2004), which can be quite arbitrary.

1174 Despite those limits, the study of the calcaneo-astragalar complex still provides some 1175 insights regarding the lifestyle of rodents. Even through comparative anatomy, arboreal climbers, 1176 terrestrial jumpers/cursors, and fossorial species can be discriminated relatively easily (Candela 1177 and Picasso, 2008, and discussion above). From a paleontological point of view, this type of 1178 comparative study represents a new source of behavioural and ecological data for fossil rodents, 
1179 independent and comparable to other data, such as diet from dental categories (e.g., Vianey-

1180 Liaud, 1991) or tooth wear (e.g., Gomes Rodrigues et al., 2009), to improve the reconstructions

1181 of the ecology of extinct species.

1182

1183 Acknowledgements : We thank the MNHN and UM collections for lending several specimens, 1184 and for allowing SG to visit their rodent collections ; François Catzeflis for lending the specimen 1185 of Proechimys cuvieri ; Thierry Noël and Marc Vianey-Liaud for lending some dissection tools ; 1186 Camille Martinand-Mari and Emilie Liabeuf-Le Goff who offered access to the dissection room. 1187 We are also grateful to J.X. Samuels and one anonymous reviewer for their helpful comments on 1188 the manuscript.

\section{References :}

1192 Antoine, P. O., Marivaux, L., Croft, D. A., Billet, G., Ganerød, M., Jaramillo, C., Martin, T., Orliac, M., Tejada, J., Altamirano A. J., Duranton, F., Fanjat, G., Rousse, S., and Gismondi, R. S. (2011). 'Middle Eocene rodents from Peruvian Amazonia reveal the pattern and timing of caviomorph origins and biogeography', Proceedings of the Royal Society B: Biological Sciences, 279(1732), 1319-1326.

Aulagnier, S. and Granjon, L. (2008), 'Psammomys obesus', In: IUCN 2013. IUCN Red List of Threatened Species. Version 2013.2. <www.iucnredlist.org>.

Barash, D. P. (1976). 'Social behaviour and individual differences in free-living Alpine marmots (Marmota marmota)', Animal Behaviour, 24(1), 27-35.

Batsaikhan, N., Tsytsulina, K., Formozov, N. and Sheftel, B. (2008), 'Microtus gregalis', In: IUCN 2013. IUCN Red List of Threatened Species. Version 2013.2. $<$ www.iucnredlist.org $>$.

Biknevicius, A. R. (1993). 'Biochemical scaling of limb bones and differential limb use in caviomorph rodents', Journal of Mammalogy, 74(1), 95-107.

Blumberg-Feldman, H., and Eilam, D. (1995). 'Postnatal development of synchronous stepping in the gerbil (Gerbillus dasyurus)', The Journal of experimental biology, 198(2), 363372.

1209 Boero, D. L. (2003) 'Long-term dynamics of space and summer resource use in the alpine 
marmot (Marmota marmota L.)', Ethology Ecology and Evolution, 15(4), 309-327.

1211 Brannen, T. A. (1979) The hind limb myology of the laboratory mouse, Mus musculus with

1212 comparisons to other rodent genera. Doctoral dissertation, Kansas State University.

1213 Buttigieg PL, Ramette A (2014) 'A Guide to Statistical Analysis in Microbial Ecology: a community-focused, living review of multivariate data analyses', FEMS Microbiology Ecology, 90: 543-550. [Online] "https://dx.doi.org/10.1111/1574-6941.12437".

1216 Candela, A., and Picasso, B. (2008) 'Functional anatomy of the limbs of Erethizontidae (Rodentia, Caviomorpha): indicators of locomotor behavior in Miocene porcupines', Journal of Morphology, 269(5), 552-593.

Carrano, T. (1997), 'Morphological indicators of foot posture in mammals: a statistical and biomechanical analysis', Zoological Journal of the Linnean Society, 121(1), 77-104.

Cassini, M. H. (1991) 'Foraging under Predation Risk in the Wild Guinea Pig Cavia aperea', Oikos, 62(1), 20-24.

Catzeflis, F., Weksler, and Bonvicino, C. (2008), 'Myoprocta acouchy', In: IUCN 2015. The IUCN Red List of Threatened species. Version 2015.2. <www.iucnredlist.org>.

Claude, J. (2008) Morphometrics with R. Springer Science and Business Media.

Çolak, G., and Çolak, E. (2007), 'Taxonomic status of the genus Spermophilus (Mammalia: Rodentia) in Turkey and Iran with description of a new species', Zootaxa, 1529, 1-15.

D'adamo, P., Guichón, L., Bó, R. F., and Cassini, H. (2000), 'Habitat use by coypu Myocastor coypus in agro- systems of the Argentinean Pampas', Acta Theriologica, 45(1), 25-34.

Dagosto, M. (1986) The joints of the tarsus in the strepsirhine primates. Doctoral dissertation, University of New York, New York.

Dagosto, M. (1988), 'Implications of postcranial evidence for the origin of euprimates', Journal of Human Evolution, 17, 35-56.

Dagosto, M. (1993), 'Postcranial anatomy and locomotor behavior in Eocene primates', In: Gebo, D.L. (Ed.), Postcranial Adaptation in Nonhuman Primates. Illinois: Northern Illinois University Press, pp. 199-219.

Davidovits, P. (2012) Physics in biology and medicine. Academic press.

Eisenberg, J. F. (1975), 'The behavior patterns of desert rodents', In: Prakash, I., \& Ghosh, P. K. (Eds.), Rodents in desert environments. Springer Netherlands, pp. 189-224.

Eisenberg, J. F. (1989) Mammals of the Neotropics, Volume 1. The northern neotropics: 
Panama, Colombia, Venezuela, Guyana, Suriname, French Guiana.

1242

1243

1244

1245

1246

1247

1248

1249

1250

1251

1252

1253

1254

1255

1256

1257

1258

1259

1260

1261

1262

1263

1264

1265

1266

1267

1268

1269

1270

1271

Elissamburu, A., and De Santis, L. (2011), 'Forelimb proportions and fossorial adaptations in the scratch-digging rodent Ctenomys (Caviomorpha)', Journal of Mammalogy, 92(3), 683689.

Elissamburu, A., and Vizcaíno, S. F. (2004), 'Limb proportions and adaptations in caviomorph rodents (Rodentia: Caviomorpha)', Journal of Zoology, 262(2), 145-159.

Emmons, L. and Reid, F. (2008), 'Dasyprocta leporina', In: IUCN 2015, The IUCN Red List of Threatened Species. Version 2015.2. <www.iucnredlist.org>.

Emry, R. J., and Thorington, R. W. (1982) Descriptive and comparative osteology of the oldest fossil squirrel Protosciurus (Rodentia: Sciuridae). Smithsonian Institution Press.

Fabre, P. H., Hautier, L., Dimitrov, D., \& Douzery, E. J. (2012) 'A glimpse on the pattern of rodent diversification: a phylogenetic approach', BMC Evolutionary Biology, 12(1), 1.

Gebo, D. L. (1988) 'Foot morphology and locomotor adaptation in Eocene primates', Folia Primatologica, 50(1-2), 3-41.

Gebo, D. L., Dagosto, M., Beard, K. C., and Qi, T. (2001) 'Middle Eocene primate tarsals from China: implications for haplorhine evolution', American journal of physical anthropology, 116(2), 83-107.

Gebo, D. L., Dagosto, M., and Rose, K. D. (1991), 'Foot morphology and evolution in early Eocene Cantius', American Journal of Physical Anthropology, 86(1), 51-73.

Gebo, D., Simons, E., (1987), 'Morphology and locomotor adaptations of the foot in early Oligocene anthropoids', American Journal of Physical Anthropology, 74, 83-101.

Gomes Rodrigues, H., Merceron, G., \& Viriot, L. (2009), 'Dental microwear patterns of extant and extinct Muridae (Rodentia, Mammalia) : ecological implications', Naturwissenschaften, 96(4), 537-542.

Gouat, P., and Gouat, J. (1987), 'Le répertoire comportemental du goundi Ctenodactylus gundi (Rongeurs, Ctenodactylidae). I. Description', Mammalia, 51(1), 3-26.

Grubb, P. and Ekué, M.R.M. (2008), 'Funisciurus anerythrus', In: IUCN 2015, The IUCN Red List of Threatened Species. Version 2015.2. <www.iucnredlist.org>.

Grubb, P., Amori, G., de Smet, K. and Bertolino, S. (2008), 'Hystrix cristata', In: IUCN 2015, The IUCN Red List of Threatened Species. Version 2015.2. <www.iucnredlist.org>.

Guichón, M. L., Benitez, V. B., Abba, A., Borgnia, M., and Cassini, M. H. (2003), 'Foraging 
1272

1273

1274

1275

1276

1277

1278

1279

1280

1281

1282

1283

1284

1285

1286

1287

1288

1289

1290

1291

1292

1293

1294

1295

1296

1297

1298

1299

1300

1301

1302

behaviour of coypus Myocastor coypus: why do coypus consume aquatic plants?', Acta Oecologica, 24(5), 241-246.

Guillotin, M. (1981) Données écologiques sur les petits rongeurs forestiers terrestres de Guyane française. Doctoral dissertation, Université des Sciences et Techniques du Languedoc, Montpellier.

Hanski, I. K., Stevens, P. C., Ihalempiä, P., and Selonen, V. (2000), 'Home-range size, movements, and nest-site use in the Siberian flying squirrel, Pteromys volans', Journal of Mammalogy, 81(3), 798-809.

Happold, D. C. D. (1967), 'Biology of the jerboa, Jaculus jaculus butleri (Rodentia, Dipodidae), in the Sudan', Journal of Zoology, 151(2), 257-275.

Herrero, J., García González, R., and García Serrano, A. (2002), 'Research on the alpine marmot (Marmota marmota) in the Spanish Pyrenees', in International Marmot Network (ed.), Holarctic marmots as a factor of biodiversity, Proceedings of the $3 d$ International Conference on Marmots (Cheboksary, Chuvash Republic, Russia 25-30 August 1997). Moscow, ABF P. H., pp. 190-197.

Heth, G. (1989), 'Burrow patterns of the mole rat Spalax ehrenbergi in two soil types (terra rossa and rendzina) in Mount Carmel, Israel', Journal of Zoology, 217(1), 39-56.

Heth, G., Golenberg, E. M., and Nevo, E. (1989), 'Foraging strategy in a subterranean rodent, Spalax ehrenbergi: a test case for optimal foraging theory', Oecologia, 79(4), 496-505.

Hildebrand, M. (1978), 'Insertions and Functions of Certain Flexor Muscles in the Hind Leg of Rodents', Journal of Morphology, 155(1),111-122.

Hildebrand M. (1985a) 'Walking and running'. In: Hildebrand M, Bramble DM, Liem KF, Wake DB, editors. Functional Vertebrate Morphology. Cambridge, MA: Harvard University Press. pp. 38-57.

Hildebrand M. (1985b) 'Digging in quadrupeds'. In: Hildebrand M, Bramble DM, Liem KF, Wake DB, editors. Functional vertebrate morphology. Cambridge, MA: Harvard University Press. pp. 89-109.

Hildebrand, M., and Goslow Jr, G. E. (2001). 'Digging, and crawling without appendages'. In : Hildebrand, M and Hurley, G.E. (eds), Analysis of Vertebrate Structure. John Wiley \& Sons, Inc.:USA.

Hoffmann, M. and Cox, N. (2008), 'Atherurus africanus', In: IUCN 2015, The IUCN Red List of 
Threatened Species. Version 2015.2. <www.iucnredlist.org>.

1304

1305

1306

Howell, K., Hutterer, R. and Ekué, M.R.M. (2008), 'Anomalurus derbianus', In: IUCN 2015, The IUCN Red List of Threatened Species. Version 2015.2. <www.iucnredlist.org>.

Jackson, A. (2000), 'Pedetes capensis', [Online] Animal Diversity Web. Accessed June 24, 2015 at http://animaldiversity.org/accounts/Pedetes_capensis/

Klingener, D. (1964), 'The Comparative Myology of Four Dipodoid Rodents (Genera Zapus, Napaeoaapus, Sicista, and Jaculus', Miscellaneous Publications Museum Of Zoology, University Of Michigan, 124.

Korth, W. W., and Samuels, J. X. (2015) 'New Rodent Material from the John Day Formation (Arikareean, Middle Oligocene to Early Miocene) of Oregon', Annals of Carnegie Museum, 83(1), 19-84.

Lagaria, A., Youlatos, D. (2006), 'Anatomical correlates to scratch digging in the forelimb of european ground squirrels (Spermophilus citellus)', Journal of Mammalogy, 87(3), 563570.

Legendre, S. (1987), 'Les communautés de mammifères et leur milieu en Europe occidentale de l'Eocène supérieur et Oligocène', Revue de paléobiologie.

Lessa, E. P., Vassallo, A. I., Verzi, D. H., and Mora, M. S. (2008), 'Evolution of morphological adaptations for digging in living and extinct ctenomyid and octodontid rodents', Biological Journal of the Linnean Society, 95(2), 267-283.

Linzey, A.V. and NatureServe (Hammerson, G. and Cannings, S.) (2013), 'Castor canadensis', In: IUCN 2015, The IUCN Red List of Threatened Species. Version 2015.2. $<$ www.iucnredlist.org $>$.

Lurz, P. W., Gurnell, J., and Magris, L. (2005), 'Sciurus vulgaris', Mammalian Species, 1-10.

Marinho-Filho, J., Queirolo, D. and Emmons, L. (2008), 'Coendou prehensilis', In: IUCN 2013, IUCN Red List of Threatened Species. Version 2013.2. <www.iucnredlist.org>.

Marivaux, L., Beard, K. C., Chaimanee, Y., Dagosto, M., Gebo, D. L., Guy, F., ... and Jaeger, J. J. (2010), 'Talar morphology, phylogenetic affinities, and locomotor adaptation of a large-bodied amphipithecid primate from the late middle eocene of Myanmar', American Journal of Physical Anthropology, 143(2), 208-222.

Marivaux, L., Salas-Gismondi, R., Tejada, J., Billet, G., Louterbach, M., Vinkg, J., Bailleul, J., Roddaz, M., Antoine, P.-O. (2012), 'A platyrrhine talus from the early Miocene of Peru 
1334

1335

1336

1337

1338

1339

1340

1341

1342

1343

1344

1345

1346

(Amazonian Madre de Dios Sub-Andean Zone)', Journal of Human Evolution, 63(5), 696-703.

Marivaux, L., Vianey-Liaud, M., and Jaeger, J. J. (2004), 'High-level phylogeny of early Tertiary rodents: dental evidence', Zoological Journal of the Linnean Society, 142(1), 105-134.

Moller, H. (1983), 'Foods and foraging behaviour of red (Sciurus vulgaris) and grey (Sciurus carolinensis) squirrels', Mammal Review, 13(2 - 4), 81-98.

Morgan, C. C. (2009), 'Geometric morphometrics of the scapula of South American caviomorph rodents (Rodentia: Hystricognathi): form, function and phylogeny', Mammalian BiologyZeitschrift für Säugetierkunde, 74(6), 497-506.

Nowak, R. M. (Ed.) (1999) Walker's Mammals of the World. JHU Press.

Ojeda, R. and Pardinas, U. (2008), 'Dolichotis patagonum', In: IUCN 2015, The IUCN Red List of Threatened Species. Version 2015.2. <www.iucnredlist.org>.

Ojeda, R., Bidau, C., Timm, T., Samudio, R. and Emmons, L. (2013), 'Dasyprocta punctata', In: IUCN 2015, The IUCN Red List of Threatened Species. Version 2015.2. $<$ www.iucnredlist.org $>$.

Perrin, C., Berre, D. A., and Le, M. (1993), 'Socio - spatial Organization and Activity Distribution of the Alpine Marmot Marmota marmota: Preliminary Results', Ethology, 93(1), 21-30.

Queirolo, D., Vieira, E. and Reid, F. (2008), 'Hydrochoerus hydrochaeris', In: IUCN 2015, The IUCN Red List of Threatened Species. Version 2015.2. <www.iucnredlist.org>.

Queirolo, D., Vieira, E., Emmons, L. and Samudio, R. (2008), 'Cuniculus paca', In: IUCN 2015, The IUCN Red List of Threatened Species. Version 2015.2. <www.iucnredlist.org>.

Rajamani, N., Molur, S. and Nameer, P.O. (2010), 'Ratufa indica', In: IUCN 2015, The IUCN Red List of Threatened Species. Version 2015.2. <www.iucnredlist.org>.

Rood, J. P. (1972), 'Ecological and behavioural comparisons of three genera of Argentine cavies', Animal Behaviour Monographs, 5, 1-IN4.

Rose, K. D. and Chinnery, B. J. (2004), 'The postcranial skeleton of early Eocene rodents', Bulletin of Carnegie Museum of Natural History, 211-244.

Samuels, J. X., and Van Valkenburgh, B. (2008), 'Skeletal indicators of locomotor adaptations in living and extinct rodents', Journal of morphology, 269(11), 1387-1411.

Schmidt, A., and Fischer, M. S. (2011), 'The kinematic consequences of locomotion on sloped 
arboreal substrates in a generalized (Rattus norvegicus) and a specialized (Sciurus vulgaris) rodent', The Journal of Experimental Biology, 214(15), 2544-2559.

Schröpfer, R., Klenner-Fringes, B., and Naumer, E. (1985), 'Locomotion pattern and habitat utilisation of the two jerboas Jaculus jaculus and Jaculus orientalis (Rodentia, Dipodidae)', Mammalia, 49(4), 445-454.

Soy, J. and Silva, G. (2008), 'Capromys pilorides', In IUCN 2015, The IUCN Red List of Threatened Species. Version 2015.2. <www.iucnredlist.org>.

Spotorno, A. E., Zuleta, C. A., Valladares, J. P., Deane, A. L., and Jiménez, J. E. (2004), 'Chinchilla lanigera', Mammalian species, 1-9.

Steppan, S.J., Storz, B.L. and Hoffmann, R.S. (2004) 'Nuclear DNA phylogeny of the squirrels (Mammalia: Rodentia) and the evolution of arboreality from c-myc and RAG1', Molecular phylogenetics and evolution, 30(3): 703-719.

Strasser, E. (1992), 'Hindlimb proportions, allometry, and biomechanics in Old World monkeys (Primates, Cercopithecidae)', American Journal of Physical Anthropology, 87(2), 187213.

Szalay, F. S. (1985), 'Rodent and lagomorph morphotype adaptations, origins, and relationships: some postcranial attributes analyzed', In: Luckett W. P., Hartenberger, J. P. (Eds.) Evolutionary Relationships among Rodents. Springer US, pp. 83-132.

Szalay, F. S. (2006) Evolutionary history of the marsupials and an analysis of osteological characters. Cambridge University Press.

Team, R. C. (2015) R: A language and environment for statistical computing. R foundation for Statistical Computing.

Thorington Jr, R. W., Schennum, C. E., Pappas, L. A., and Pitassy, D. (2005) 'The difficulties of identifying flying squirrels (Sciuridae: Pteromyini) in the fossil record', Journal of Vertebrate Paleontology, 25(4), 950-961.

Tsytsulina, K., Formozov, N. and Sheftel, B. (2008), 'Spermophilus fulvus', In: IUCN 2013, IUCN Red List of Threatened Species. Version 2013.2. <www.iucnredlist.org>.

Venables, W. N. and Ripley, B. D. (2002) Modern applied statistics with S. Fourth Edition. Springer, New York.

Vianey-Liaud, M. (1991), 'Les rongeurs de l'Eocène terminal et de l'Oligocène d'Europe comme indicateurs de leur environnement', Palaeogeography, Palaeoclimatology, 
1396 Palaeoecology, 85(1), 15-28.

1397 Vianey-Liaud, M., Gomes-Rodrigues, H., \& Marivaux, L. (2013), 'Early adaptive radiations of 1398 Aplodontoidea (Rodentia, Mammalia) on the Holarctic region: systematics, and 1399 phylogenetic and paleobiogeographic implications', Paläontologische Zeitschrift, 87(1), 1400 83-120.

1401 Vianey-Liaud, M., Hautier, L., Marivaux, L. (2015) 'Morphological disparity of the postcranial 1402 skeleton in rodents and its implications for paleobiological inferences: the case of the extinct Theridomyidae (Rodentia, Mammalia)'. In: Cox, F.G., Hautier, L. (Eds.), Evolution of the Rodents: Advances in Phylogenetics, Functional Morphology and Development. Cambridge University Press, Cambridge, chap.20, pp. 538-588.

Walston, J., Duckworth, J.W. and Molur, S. (2008), 'Ratufa bicolor', In: IUCN 2015, The IUCN Red List of Threatened Species. Version 2015.2. <www.iucnredlist.org>.

Weber, C. (2004), 'Erethizon dorsatum', [Online] Animal Diversity Web. Accessed June 24, 2015 at http://animaldiversity.org/accounts/Erethizon_dorsatum/

Weisbecker, V., and Schmid, S. (2007), 'Autopodial skeletal diversity in hystricognath rodents: functional and phylogenetic aspects', Mammalian Biology-Zeitschrift für Säugetierkunde, 72(1), 27-44.

Wilson, D. E., and Reeder, D. M. (Eds.). (2005) Mammal species of the world: a taxonomic and geographic reference (Vol. 12). JHU Press.

Wund, M. (2000) 'Lagidium peruanum', [Online] Animal Diversity Web. Accessed June 24, 2015 at http://animaldiversity.org/accounts/Lagidium_peruanum/

Youlatos, D., and Samaras, A. (2011), 'Arboreal locomotor and postural behaviour of European red squirrels ( Sciurus vulgaris L.) in northern Greece', Journal of Ethology, 29(2), 235242.

Zuri, I., and Terkel, J. (1996), 'Locomotor patterns, territory, and tunnel utilization in the mole rat Spalax ehrenbergi', Journal of Zoology, 240(1), 123-140.

\section{Appendices :}


1427 Appendix 1: Abbreviations (in alphabetical order)

1428

1429 ABW : Astragalus Body Width

1430 AmT : Astragalar-medial Tarsal

1431 AmTL : Astragalar-medial Tarsal facet Length

1432 ATL : Astragalus Total Length

1433 ATW : Astragalus Total Width

$1434 \mathrm{CaCu}$ : Calcaneo-Cuboid (facet)

1435 CAL : Calcaneum Anterior Length

$1436 \mathrm{CCH}$ : Calcaneum-Cuboid facet Height

1437 CCW : Calcaneum-Cuboid facet Width

1438 CPL : Calcaneum Posterior Length

1439 CTL : Calcaneum Total Length

1440 CTW : Calcaneum Total Width

1441 EL : Ectal facet Length

1442 EW : Ectal facet Width

$1443 \mathrm{HH}:$ Head Height

1444 HW : Head Width

1445 ISEM : Institut des Sciences de l'Evolution de Montpellier

1446 LBH/MBH : Lateral/Medial Body Height

$1447 \mathrm{lr} / \mathrm{mr}$ : lateral/medial radius

1448 1TAH/mTAH : lateral/medial Trochlear Arc Height

1449 LTL/MTL : Lateral/Medial Trochlear Length

1450 MNHN : Muséum National d'Histoire Naturelle

$1451 \mathrm{MH}$ : Maximum Height

$1452 \mathrm{NH}:$ Neck Height

1453 NL : Neck Length

1454 NW : Neck Width

1455 PPL : Peroneal Process Length

1456 PPW : Peroneal Process Width

1457 SL : Sustentacular Facet Length 
1458 SW : Sustentacular facet Width

1459 TH : Tuber Height

1460 TWc : Tuber width (calcaneus)

1461 TWa : Trochlear Width (astragalus)

1462 UAJ : Upper Ankle Joint

1463 UM : Université de Montpellier

1464

1465 Appendix 2 : Results from the LDA on the astragalus

1466 Prior probabilities of groups:

$1467-1$

$\begin{array}{llllllll}1468 & 0.08571429 & 0.17142857 & 0.25714286 & 0.11428571 & 0.25714286 & 0.11428571\end{array}$

1469

1470 Group means:

1471

ABW ATL

ATW EL EW

HH HW

$147210.27952950 .71575860 .3997427-0.04640842-0.2205371-0.2771638-0.11274398$

$147320.36143280 .62031640 .4622937-0.01964534-0.2461056-0.3552226-0.09653397$

$147430.29147430 .63513210 .51818960 .01003638-0.2964897-0.4734017-0.07814465$

$147540.34348630 .65245690 .50395990 .01916780-0.2476862-0.3393500-0.04259003$

$147650.25734250 .64344380 .49767810 .01621850-0.2661444-0.3430905-0.10040117$

$147760.34937950 .55379500 .4640582-0.07134248-0.1209143-0.5068228-0.10807614$

1478 LBH $\quad$ LTL $\quad$ MBH $\quad$ MTL $\quad$ NL $\quad$ SL

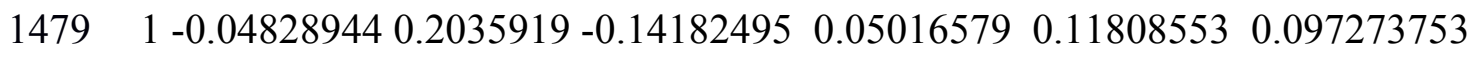

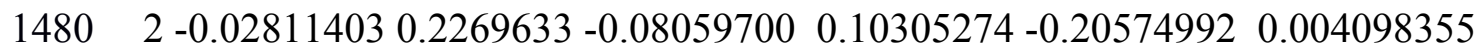

$14813-0.090207080 .2322222-0.028902900 .14349634-0.01280596-0.027459058$

$14824-0.112958060 .2015453-0.10303312-0.042008200 .08437209-0.295533580$

$1483 \quad 5-0.175643480 .1981003-0.22247530-0.06470717 \quad 0.09343663-0.025417617$

$1484 \quad 6-0.028768760 .1446314-0.04667974 \quad 0.15404345-0.187646190 .137110868$

$1485 \quad$ SW $\quad$ TW

$1486 \quad 1-0.8578186-0.15936139$

$1487 \quad 2-0.6960436-0.05014519$

$1488 \quad 3-0.7481649-0.07497487$ 
$1489 \quad 4-0.5641562-0.05767271$

$1490 \quad 5-0.5403148 \quad 0.03197464$

$1491 \quad 6-0.7001367-0.03263137$

1492

1493 Coefficients of linear discriminants:

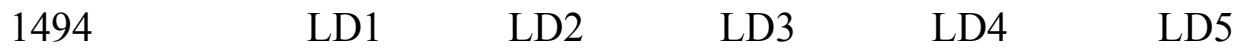

1495 ABW $0.52981258 .040218417 .0061985 \quad 1.3442958-0.1399471$

1496 ATL $-8.8882780-5.67286746 .65964150 .760411611 .5093998$

1497 ATW $7.5596580-1.5975077-8.96947373 .63098001 .4114182$

1498 EL $10.0707438-1.0919534-3.2055427-1.9495202-0.6091934$

1499 EW $\quad-4.24465842 .1184284-3.3872345-5.3710509-2.4733596$

1500 HH $-10.39046098 .1813388-5.6211747 \quad 5.3682597-0.9179537$

1501 HW $9.12111960 .8374204-3.4674061 \quad 1.4259092-2.1234192$

1502 LBH $-7.5654175-1.57996937 .4150531-0.14686580 .7318520$

1503 LTL $7.04625748 .8786241-3.63920358 .28030448 .4320446$

1504 MBH $4.28783513 .34715246 .7844033-2.2577348-0.4685301$

1505 MTL $7.2494378 \quad 2.7307732-7.5413673 \quad 0.3276344-0.8076582$

$1506 \quad \mathrm{NL} \quad 2.9710925 \quad 0.1671214-0.1328525 \quad 2.7764252-5.7927814$

1507 SL $-1.80859365 .8271209-5.2674725-1.7001297 \quad 1.0190663$

1508 SW $\quad-3.0465696-7.3689424 \quad 6.7211866-4.01410003 .0599196$

1509 Twa $-0.3733754-8.2921474-5.3921383-3.20601822 .5812758$

1510

1511 Proportion of trace:

1512 LD1 LD2 LD3 LD4 LD5

$1513 \quad 0.36320 .34500 .15570 .10740 .0288$

1514

1515 Appendix 3 : Results from the LDA on the calcaneus

1516

1517 Prior probabilities of groups:

$\begin{array}{lllllll}1518 & 1 & 2 & 3 & 4 & 5 & 6\end{array}$

$\begin{array}{llllllll}1519 & 0.08823529 & 0.17647059 & 0.26470588 & 0.11764706 & 0.23529412 & 0.11764706\end{array}$ 
1520

1521 Group means:

1522

$\mathrm{CAL} \quad \mathrm{CCH}$

CCW CPL

CTL CTW

EL

$152310.5428081-0.3241327-0.64340110 .67687601 .4574120 .3792084-0.27481128$

$152420.4556747-0.2552781-0.57963930 .69937461 .3680480 .3452228-0.16196112$

$152530.3780853-0.2766946-0.50225090 .59133001 .2819440 .4633359-0.05037334$

$152640.2089128-0.1466701-0.32344800 .49328731 .2550940 .6599861-0.28739921$

$152750.1651350-0.2302089-0.34352790 .60519731 .1843520 .6231515-0.04269456$

$152860.2371690-0.2852894-0.45610870 .80749161 .2665820 .3870291-0.14270534$

1529 EW $\mathrm{MH} \quad \mathrm{NH} \quad \mathrm{NW}$ PPL $\quad$ SL $\quad$ SW

$1530 \quad 1-0.61402100 .45216750 .10755490-0.3330313-0.4733468-0.2283696-0.8053747$

$15312-0.58607350 .32463630 .09351646-0.3469678-0.3557590-0.3785312-0.5797817$

$15323-0.48108290 .29699790 .11604921-0.3797099-0.3081778-0.5391912-0.6557702$

$15334-0.64707260 .19020210 .01698257-0.3187746-0.1930455-0.5015808-0.5774419$

$15345-0.55595760 .23119150 .11212594-0.5393386-0.2687376-0.2767090-0.5746003$

$15356-0.42949130 .30217050 .12125905-0.4025320-0.4009309-0.2787967-0.6274753$

1536 TH TW

$1537 \quad 10.07867086 \quad 0.00179077$

$1538 \quad 20.07368905-0.11617026$

$153930.12681126-0.06130275$

$1540 \quad 40.15181561 \quad 0.01915256$

$154150.17980588-0.26918424$

$1542 \quad 60.03055953-0.12893161$

1543

1544 Coefficients of linear discriminants:

1545 LD1 LD2 LD3 LD4 LD5

$\begin{array}{lllllll}1546 & \text { CAL } & 6.4174449 & 3.50511872 & -7.07993865 & 0.6671641 & 2.2878551\end{array}$

$1547 \mathrm{CCH} \quad 7.3246441 \quad-4.73155266 \quad 7.61986282 \quad-6.9808590-3.0182532$

1548 CCW $4.5999642 \quad-9.36142862-0.30856777 \quad-5.9969305-2.3251114$

1549 CPL $-0.4059243 \quad 4.04789287 \quad 0.04632179 \quad 1.0338494 \quad 0.5343113$

1550 CTL -23.6936015 $\quad-7.35723085 \quad 16.71228120 \quad 1.2877966-4.8971000$ 
1551 CTW $4.5413249 \quad 12.32735358 \quad-5.17462522 \quad 2.3889705-3.3709005$

$1552 \quad$ EL $0.2910011-4.44676585 \quad-2.42225487-4.15162481 .0831386$

$1553 \quad$ EW $3.8885261 \quad-4.11006743 \quad 1.66413085$-2.0640945 -3.1014178

$1554 \quad \mathrm{MH} \quad-0.7069701 \quad 5.14917621-12.26742443 \quad 2.59387953 .9900014$

$1555 \mathrm{NH} \quad-2.0762885 \quad-1.20067995 \quad 11.50849609-17.4323781-2.7658429$

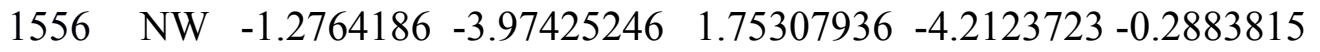

$1557 \quad$ PPL $-2.9196060 \quad 1.92081145 \quad 2.056886635 \quad 4.65653812 .5390342$

$1558 \quad$ SL $\quad-5.6253588 \quad 4.35642986 \quad 0.16891955-1.4427326-3.4376052$

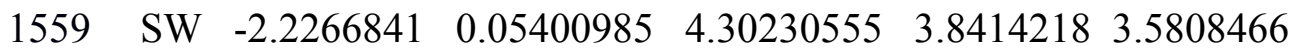

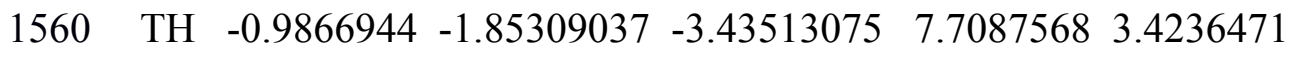

1561 Twc $-0.3359066-11.67277792 \quad-3.74125392 \quad-1.6726337-4.5590015$

1562

1563 Proportion of trace:

1564 LD1 LD2 LD3 LD4 LD5

$1565 \quad 0.52060 .29930 .07580 .05920 .0451$

1566

1567 


\section{Figure 1}

\section{Structures and insertions on the astragalus and calcaneus}

Fig. 1-A Calcaneus of Marmota marmota (as an example) to show the main structures of the bone, in plantar (left) and dorsal (right) views. Numbers correspond to colored areas (red: tendon insertions; orange: tendon origins; light blue: passage of tendon; dark blue, ligament insertions. 1: insertion of Achilles tendon ( $M$. soleus and M. gastrocnemius); 2: origin of $M$. flexor digitorum brevis (may be continuous with the insertion of the Achilles tendon); 3 : concave area on which is inserted a ligament attached to the distal head of the crus; 4: area along which the tendons of $M$. flexor fibularis and $M$. flexor digiti slide (but do not attach); 5 : area along which the tendons of $M$. peroneus longus and brevis slide; 6 : area of insertion of ligaments linked to the cuboïd and metatarsal 4 . On the lateral edge of the area is a ligament linked to the plantar side of the astragalus. 7: area of insertion of a ligament, generally linked to metatarsal 1. In $P$. cuvieri the area is concave and a small adductor muscle for digit 1 originates from there. 8: Origin of $M$. flexor digiti $V$ brevis; 9: along this area are inserted fibers forming a slender ligament, linked to the plantar side of the astragalus. 10: concave area in which is inserted a ligament linked with the plantar side of the astragalus. 11: area of insertions of two ligaments, one linked with the neck of the astragalus (area 3 in Fig. 1-B), the other with the navicular. Posteriorly, on the medial edge of this area, are attached ligaments linked with the medial tarsal bone and the ectocuneiform or mesocuneiform. 12: area of insertion of connective tissue linked to metatarsal 4.

Fig. 1-B Astragalus of Marmota marmota (as an example) in plantar (left) and dorsal (right) views. As in Fig. 1-A, areas of ligament insertions are represented. 1: sulcus, insertion of the ligament linked to the dorsal side of the calcaneus (9 in Fig. 1-A). 2: area of insertion of connective tissue linking the astragalus with the medial malleolus and entocuneiform bone. 3: area of insertion of a ligament linked to the dorsal side of the calcaneus (11 in Fig. 1-A). 4: area of insertion of connective tissue linked with the navicular and medial tarsal bones (see Hildebrand 1978 and Szalay 1985 for details on the medial tarsal bone). 5: area of insertion of the deltoïd ligament. 
A.

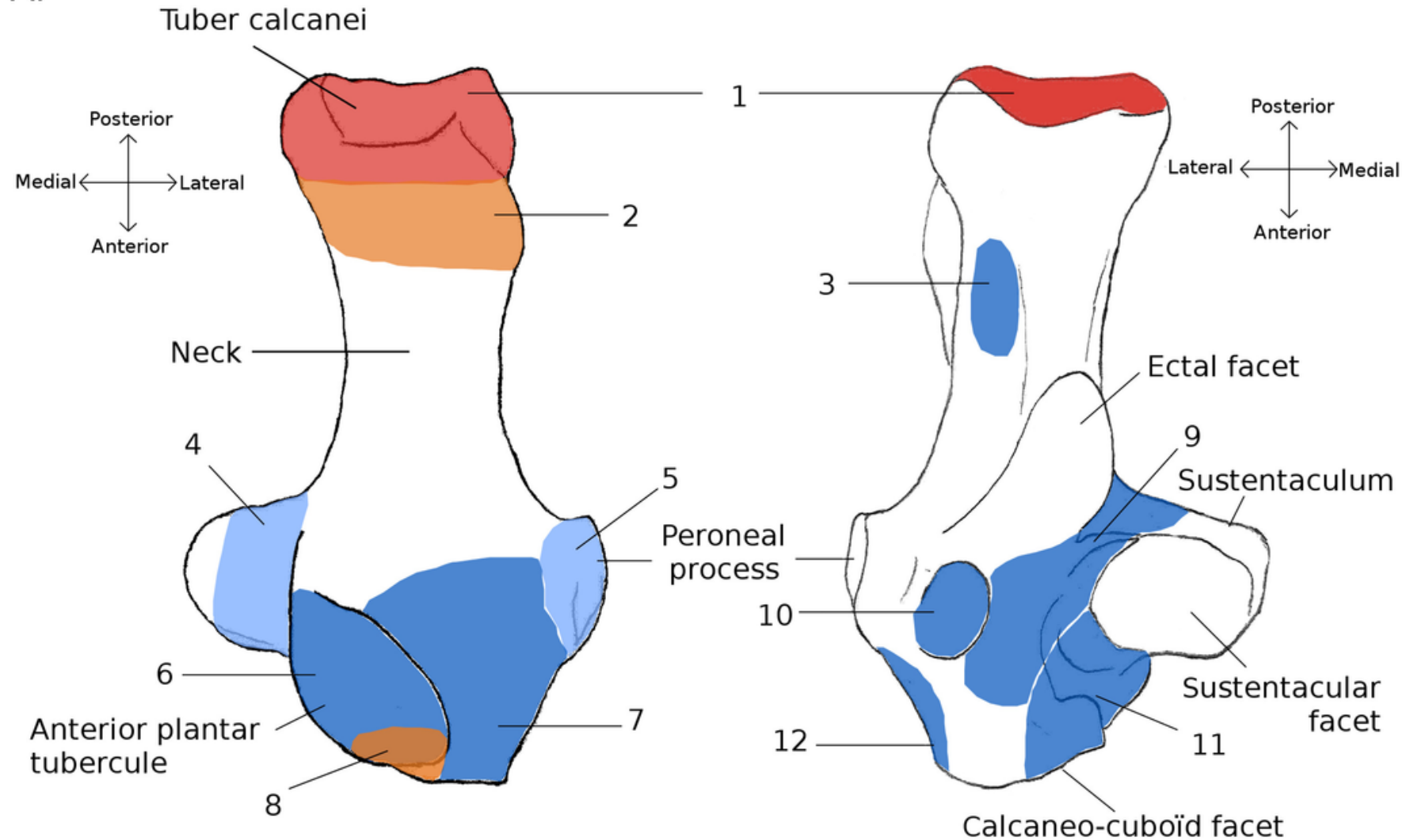

B. $\stackrel{\text { Post. }}{\stackrel{\uparrow}{\longrightarrow} \text { Lat. }}$
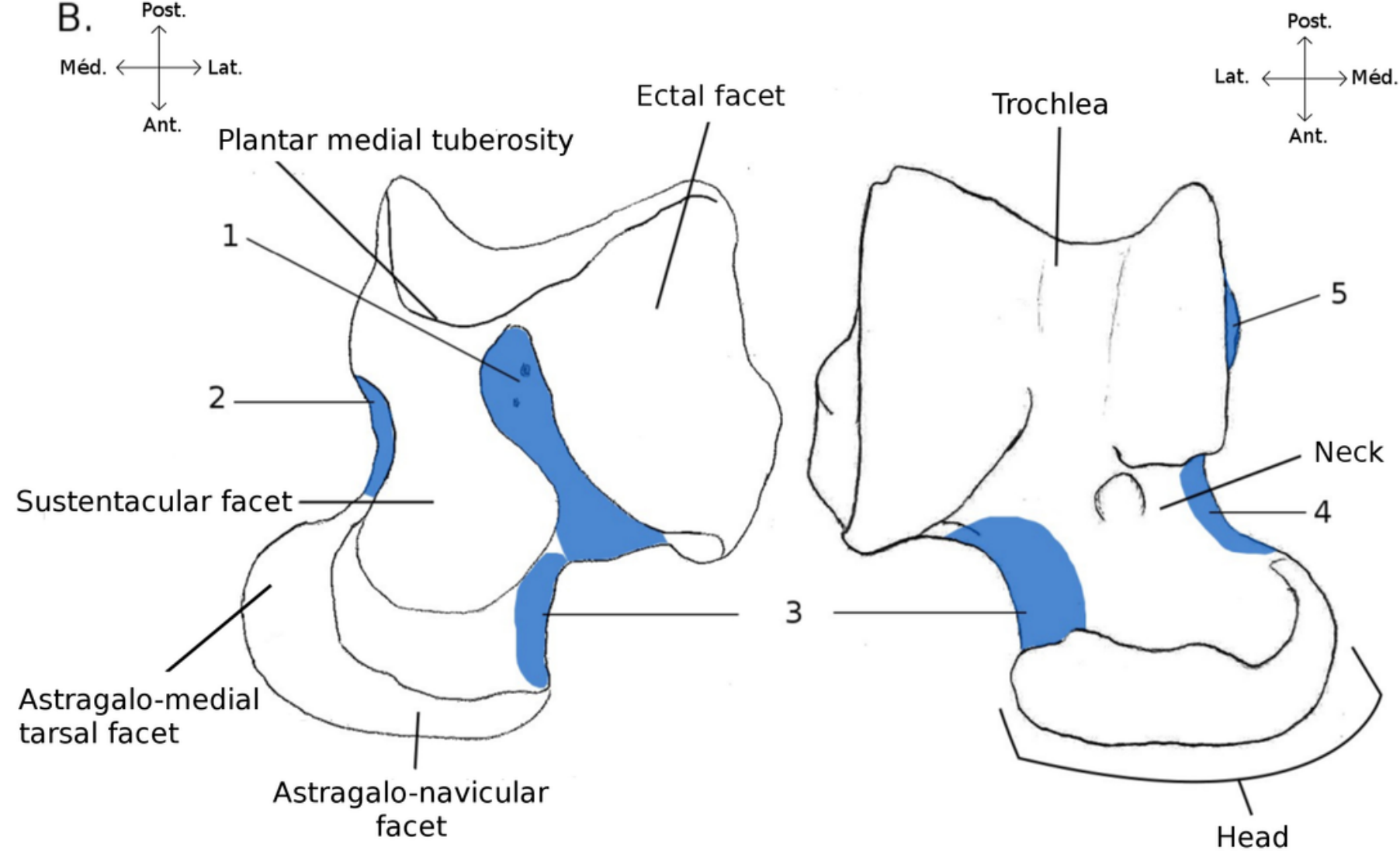
Figure 2

Measurements used in the study

Linear measurements of the calcaneus and astragalus, abbreviations are given in Appendix

1.

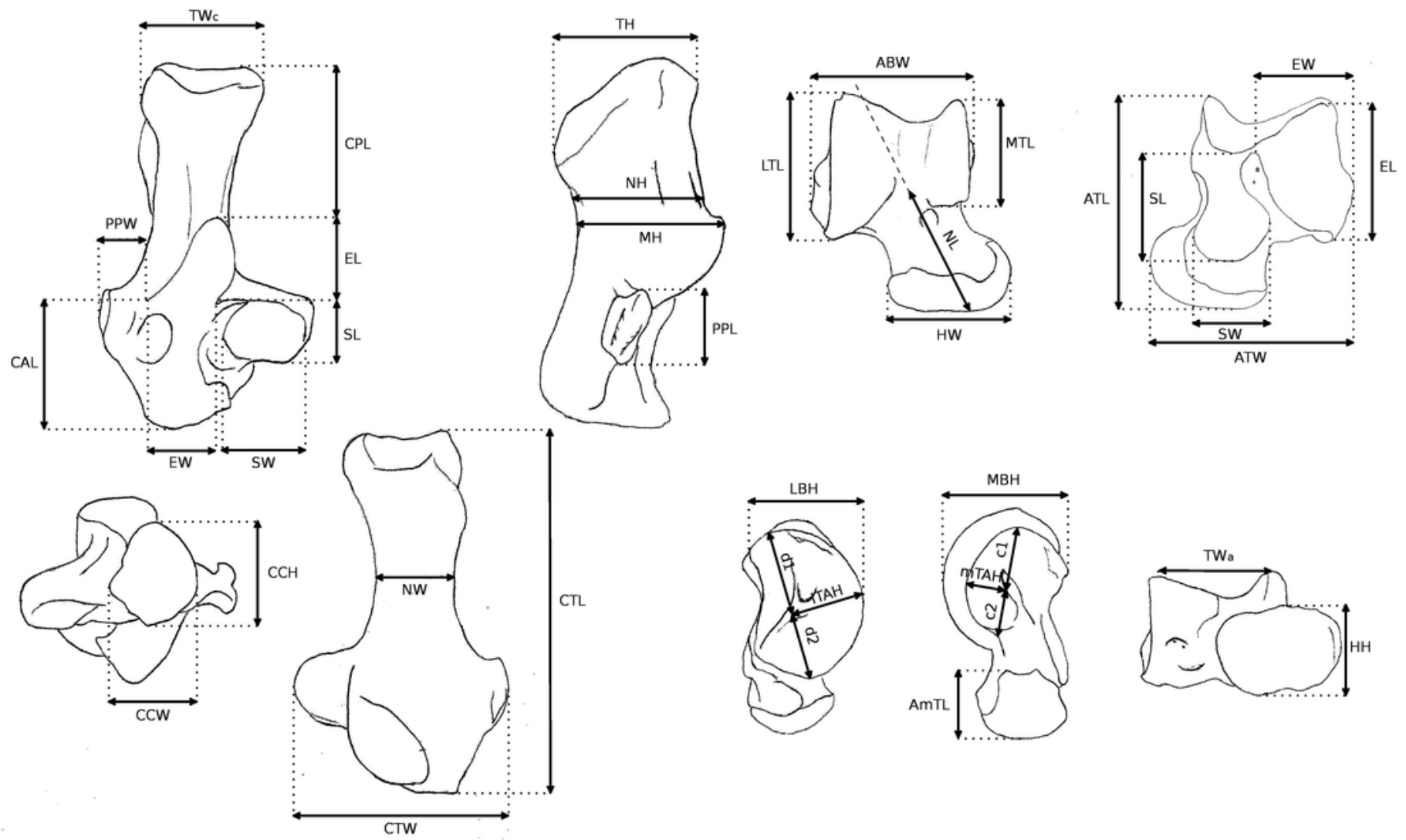


Figure 3

Drawings of calcanei and astragali of squirrel related species

Calcanei (dorsal and anterior views) and astragali (dorsal and plantar views) of squirrelrelated clade specimens described in Results - Osteological descriptions - (A) Marmota marmota; (B) Spermophilus fulvus; (C) Pteromys volans; (D) Sciurus vulgaris.

A.

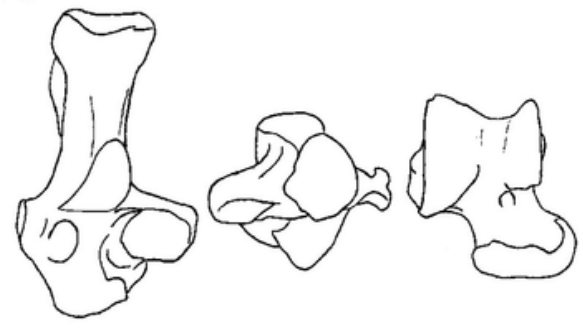

C.

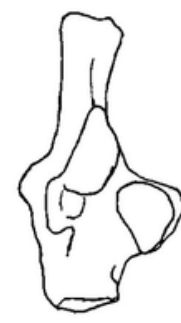

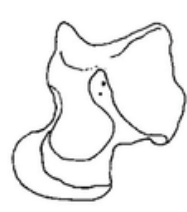
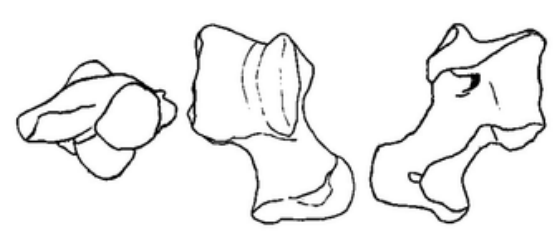

B.
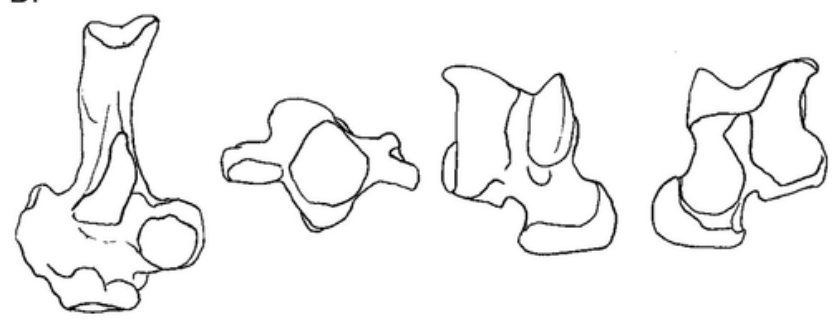

D.
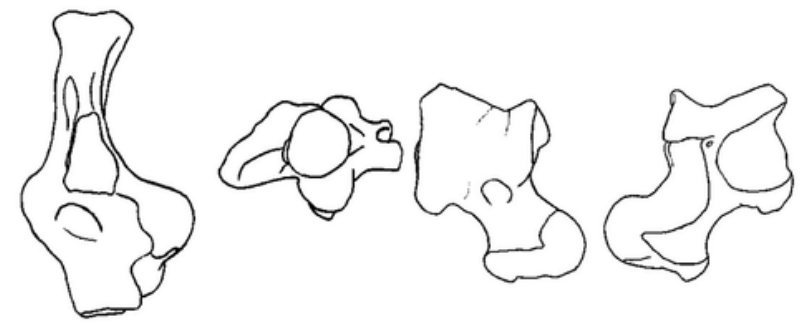
Figure 4

Drawings of calcanei and astragali of Myodonta species

Calcanei (dorsal and anterior views) and astragali (dorsal and plantar views) of Myodonta specimens described in Results - Osteological descriptions - (E) Gerbillus sp.; (F) Psammomys obesus; (G) Microtus gregalis; (H) Spalax ehrenbergi; (I) Jaculus sp..

E.
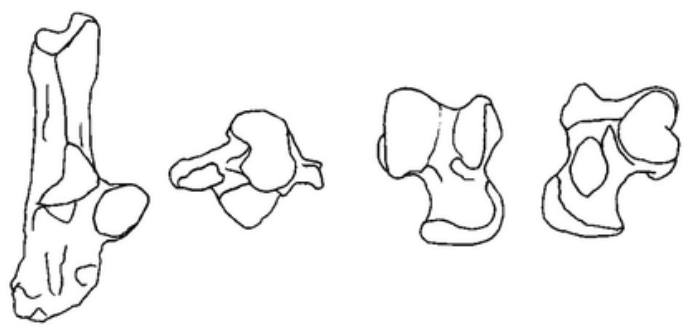

G.
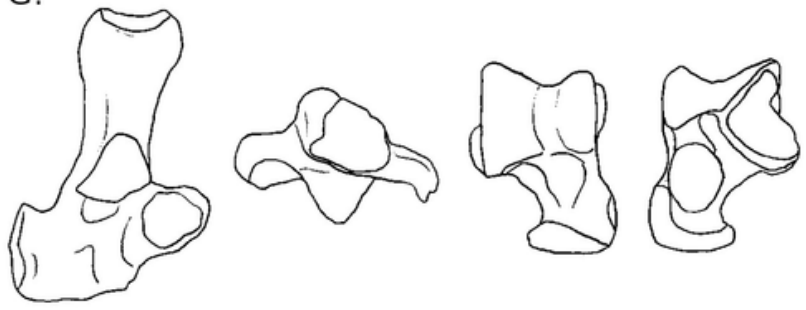

I.

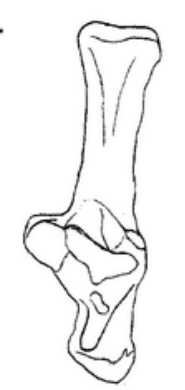

F.
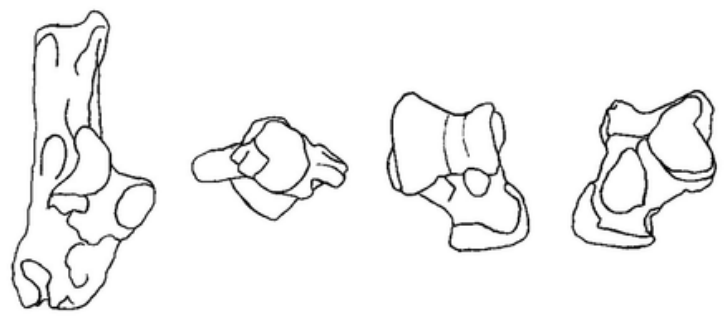

$\mathrm{H}$.

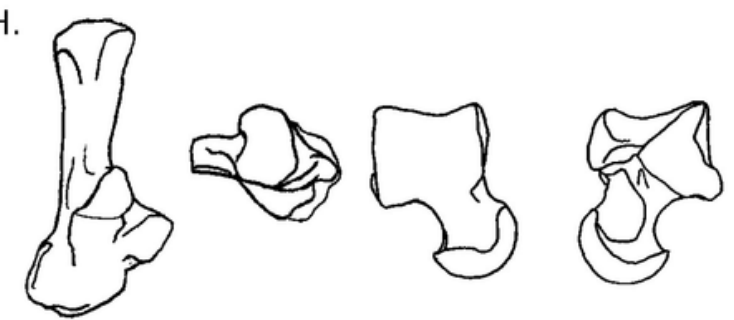




\section{Figure 5}

Drawings of calcanei and astragali of Ctenohystrica species

Calcanei (dorsal and anterior views) and astragali (dorsal and plantar views) of Ctenohystrica and Castoridae specimens described in Results - Osteological descriptions - (J) Ctenodacty/us vali ; (K) Cavia porcellus; (L) Chinchilla lanigera; (M) Coendou prehensilis; (N) Octodon degus; (O) Myocastor coypus ; (P) Proechimys cuvieri ; (Q) Castor sp..

J.

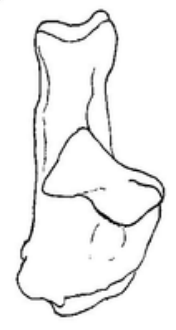

L.

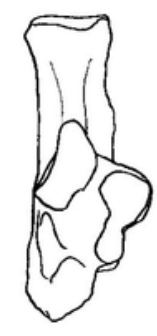

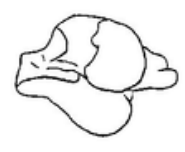
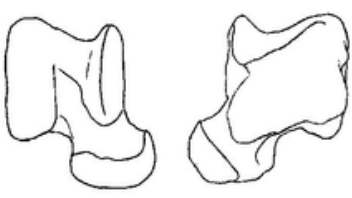

K.

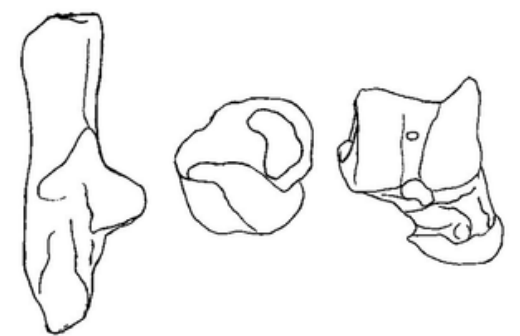

M.
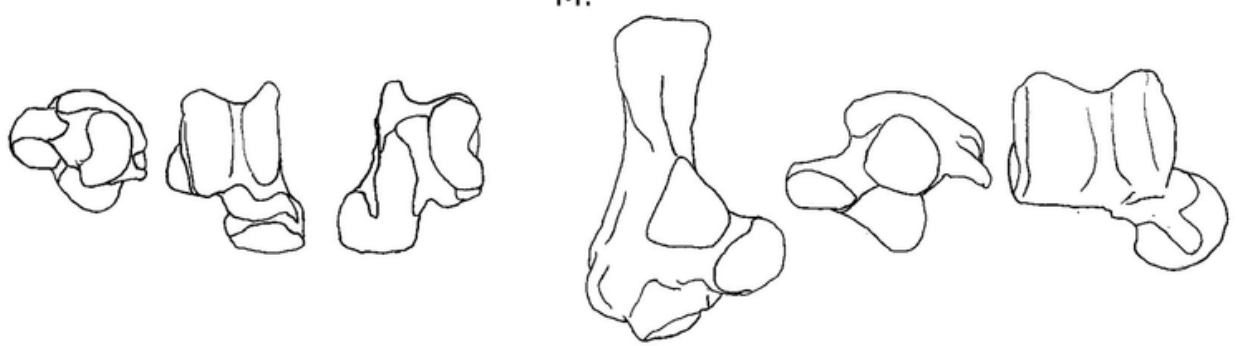
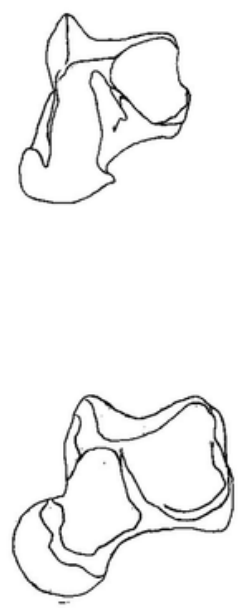

N.

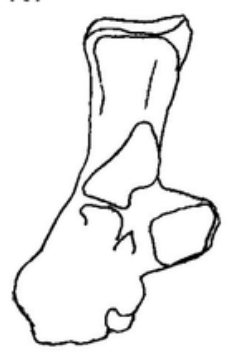

P.

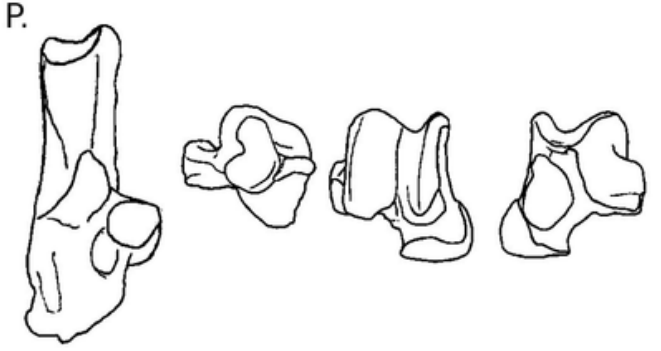

O.
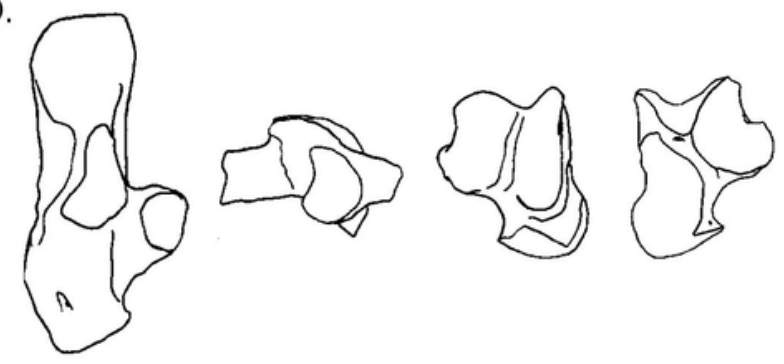

Q.
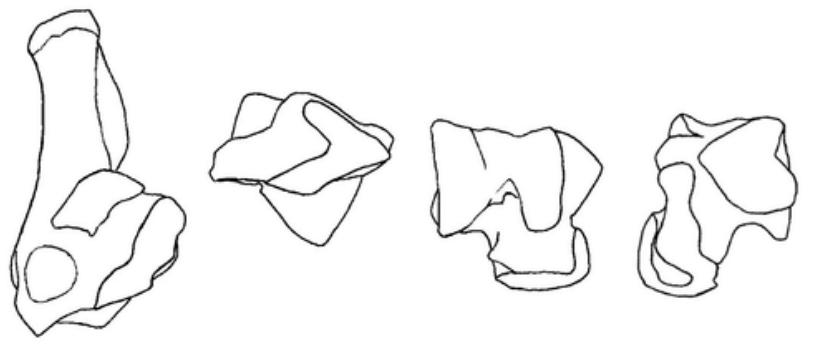


\section{Figure 6}

LDA of locomotory groups for the astragalus

Linear discriminant analysis (LD1 and LD2) of locomotory groups based on mean log-shape ratios of linear measurements of the astragalus (see Fig. 2). Each point represents the average for a species (associated with abbreviated taxon name). In grey are the jumping taxa (locomotor category 1); in yellow are the cursorial taxa (category 2); in red are generalist taxa (category 3); in brown are the fossorial taxa (category 4); in green are the arboreal climbers (category 5); in blue are the semi-aquatic taxa (category 6). Drawings are here to show one morpological example of the corresponding category. Abbreviations in bold black font are the a posteriori placements of the fossil taxa : B.la : Blainvillimys langei; E.at: Eucricetodon atavus; I.pa: Issiodoromys pauffiensis; P.go: Palaeosciurus goti; P.ga: Pseudoltinomys gaillardi. Along axes are the main variables correlated with the linear discriminant functions (variables with an asterisk are close to significance). ABW : astragalus body width ; ATL : astragalus total length ; EL : ectal facet length ; HH : head height ; LBH : lateral body height ; MBH : medial body height ; MTL : medial trochlear length ; NL : neck length ; SL : sustentacular facet length ; SW : sustentacular facet width ; TWa : trochlear width. 


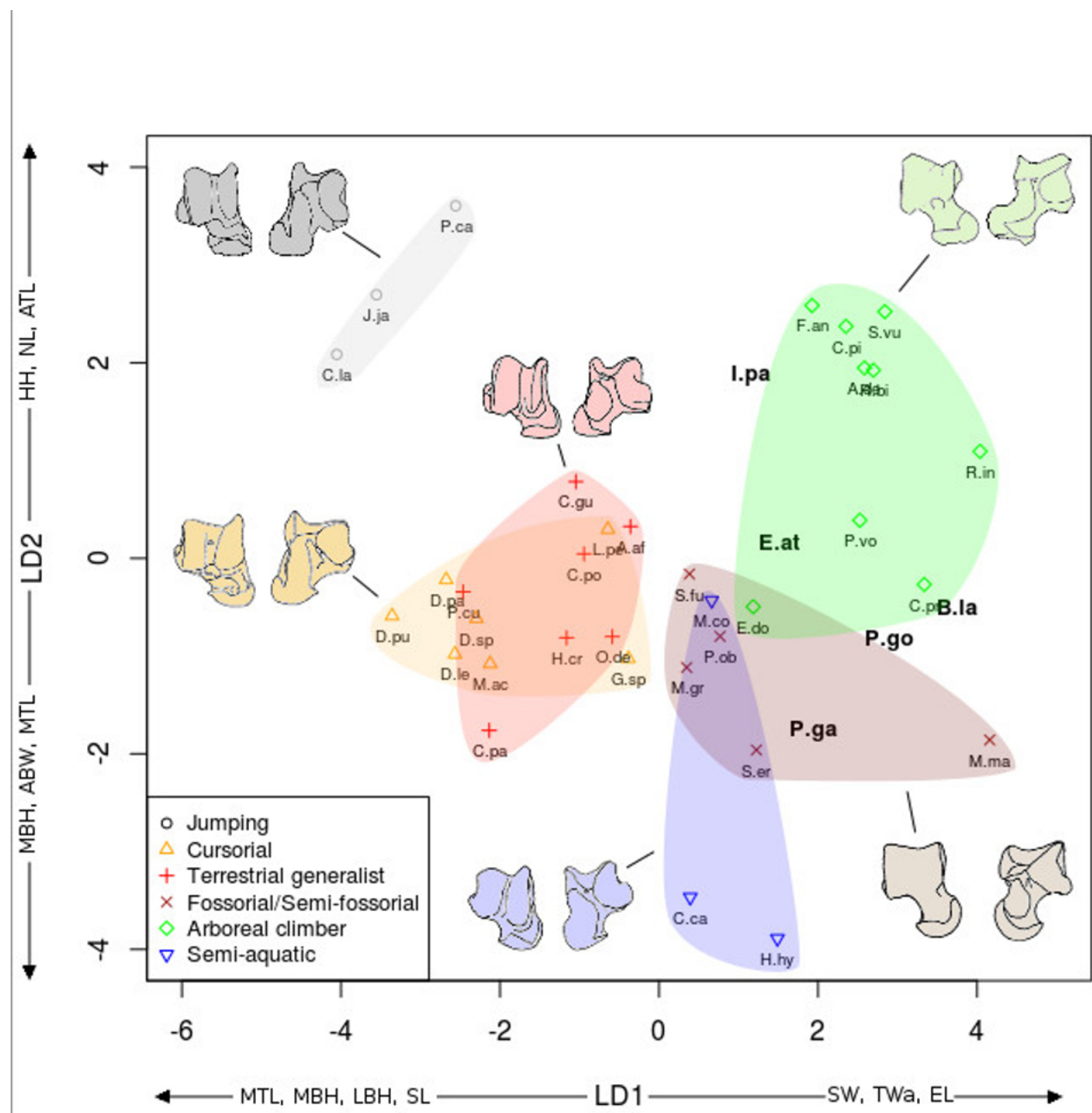




\section{Figure 7}

LDA of locomotor groups for the calcaneus

As Fig. 7 for calcaneus measurements. Abbreviations in bold black font are the a posteriori placements of the fossil taxa : B.la : Blainvillimys langei; E.at: Eucricetodon atavus; I.pa: Issiodoromys pauffiensis; P.go: Palaeosciurus goti; P.ga: Pseudoltinomys gaillardi. Along axes are the main variables correlated with the linear discriminant functions (variables with an asterisk are close to significance). CAL : calcaneus anterior length ; CCH : calcaneo-cuboid facet height ; CCW : calcaneo-cuboid facet width ; CPL : calcaneus posterior length ; CTL : calcaneus total length ; CTW : calcaneus total width ; $\mathrm{MH}$ : maximum height ; $\mathrm{NH}$ : neck height ; NW : neck width. 


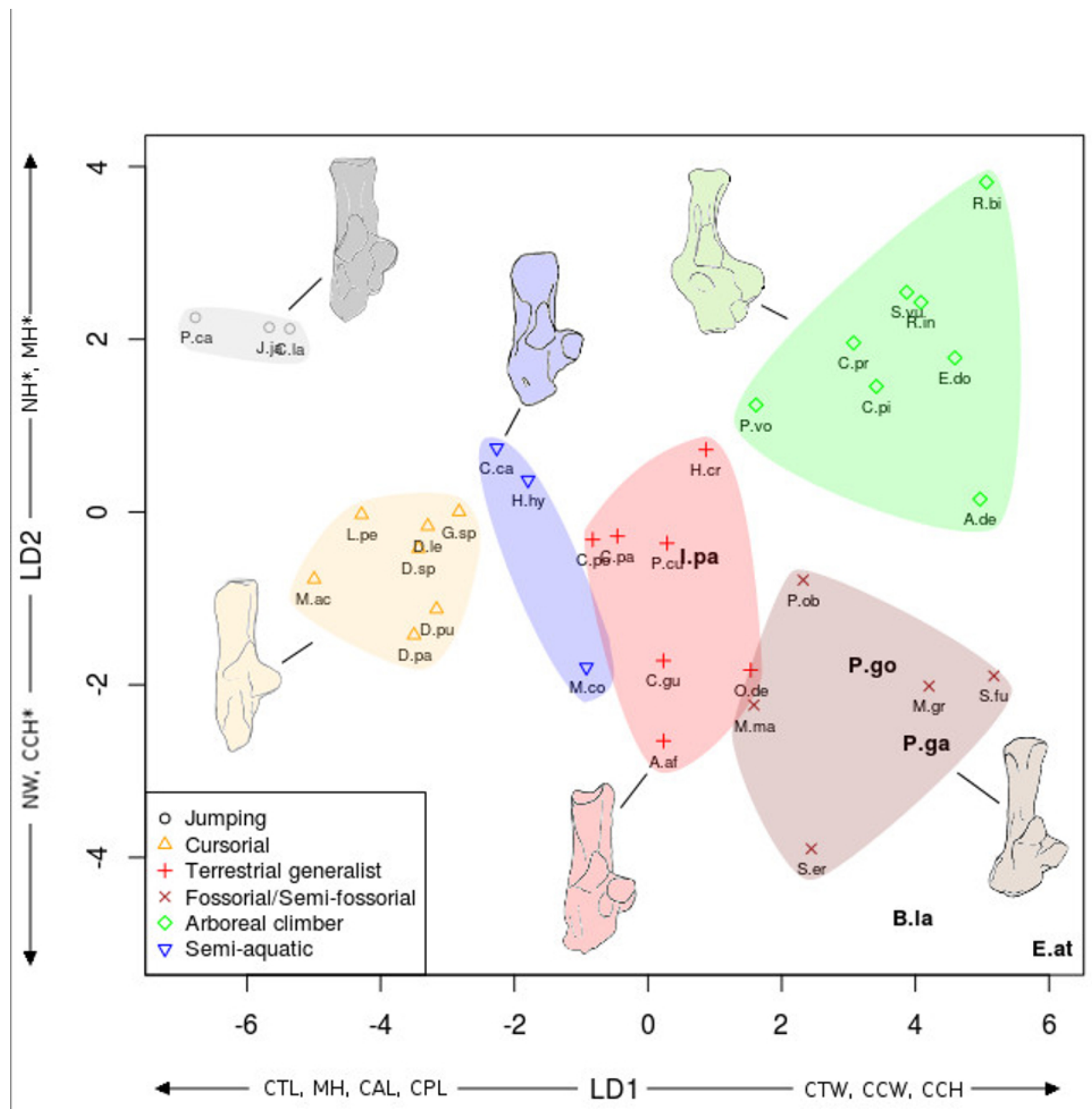




\section{Figure 8}

Drawings of the calcanei and astragali of the fossil species studied

Calcanei and astragali of fossil species studied (A) Blainvillimys langei RAV2001 (astragalus) and RAV2002 (calcaneus) (A1) astragalus, dorsal view, (A2) astragalus, plantar view, (A3) calcaneus, anterior view, (A4) calcaneus, dorsal view ; (B) Issiodoromys Pauffiensis SPV593 (astragalus) (B1) astragalus, dorsal view, (B2) astragalus, plantar view, (B3) calcaneus, dorsal view (specimen MPF213), (B4) calcaneus, anterior view (specimen SPV592). ; (C) Pseudoltinomys gaillardi RAV2003 (astragalus) and RAV2004 (calcaneus) (C1) astragalus, dorsal view, (C2) astragalus, plantar view, (C3) calcaneus, anterior view, (C4) calcaneus dorsal view ; (D) Palaeosciurus goti MGB101 (astragalus) and MGB102 (calcaneus) (D1) calcaneus, dorsal view, (D2) calcaneus, anterior view, (D3) astragalus, dorsal view, (D4) astragalus plantar view ; (E) Eucricetodon atavus RAV2005 (astragalus) and RAV2006 (calcaneus) (E1) astragalus, dorsal view, (E2) astragalus, plantar view, (E3) calcaneus, dorsal view, (E4) calcaneus, anterior view. 

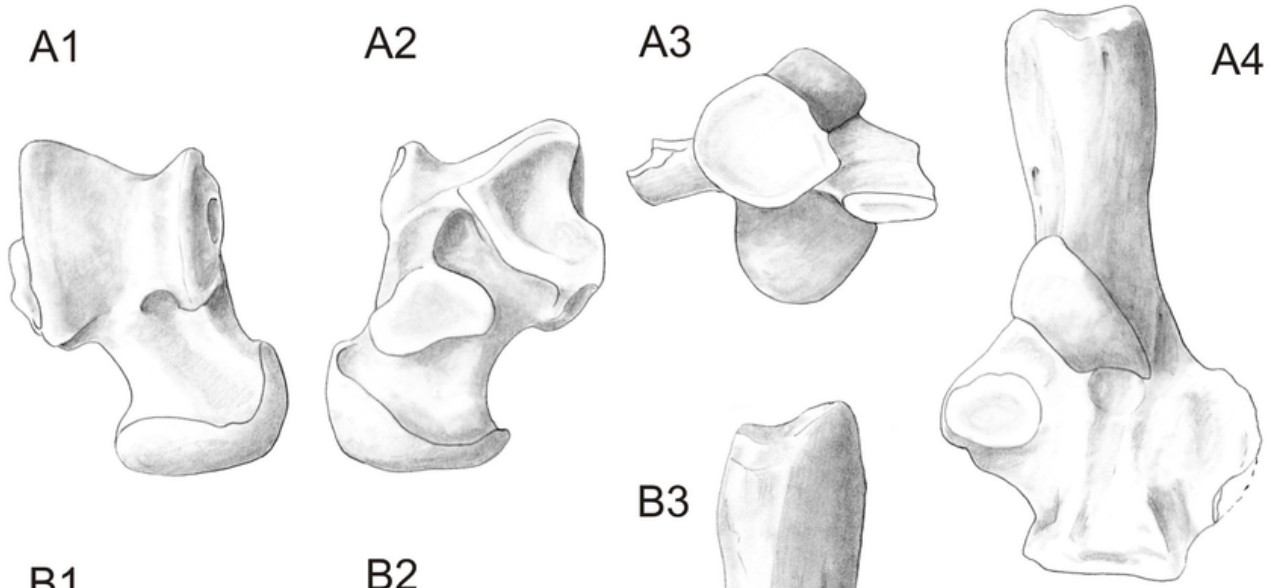

B1

B2
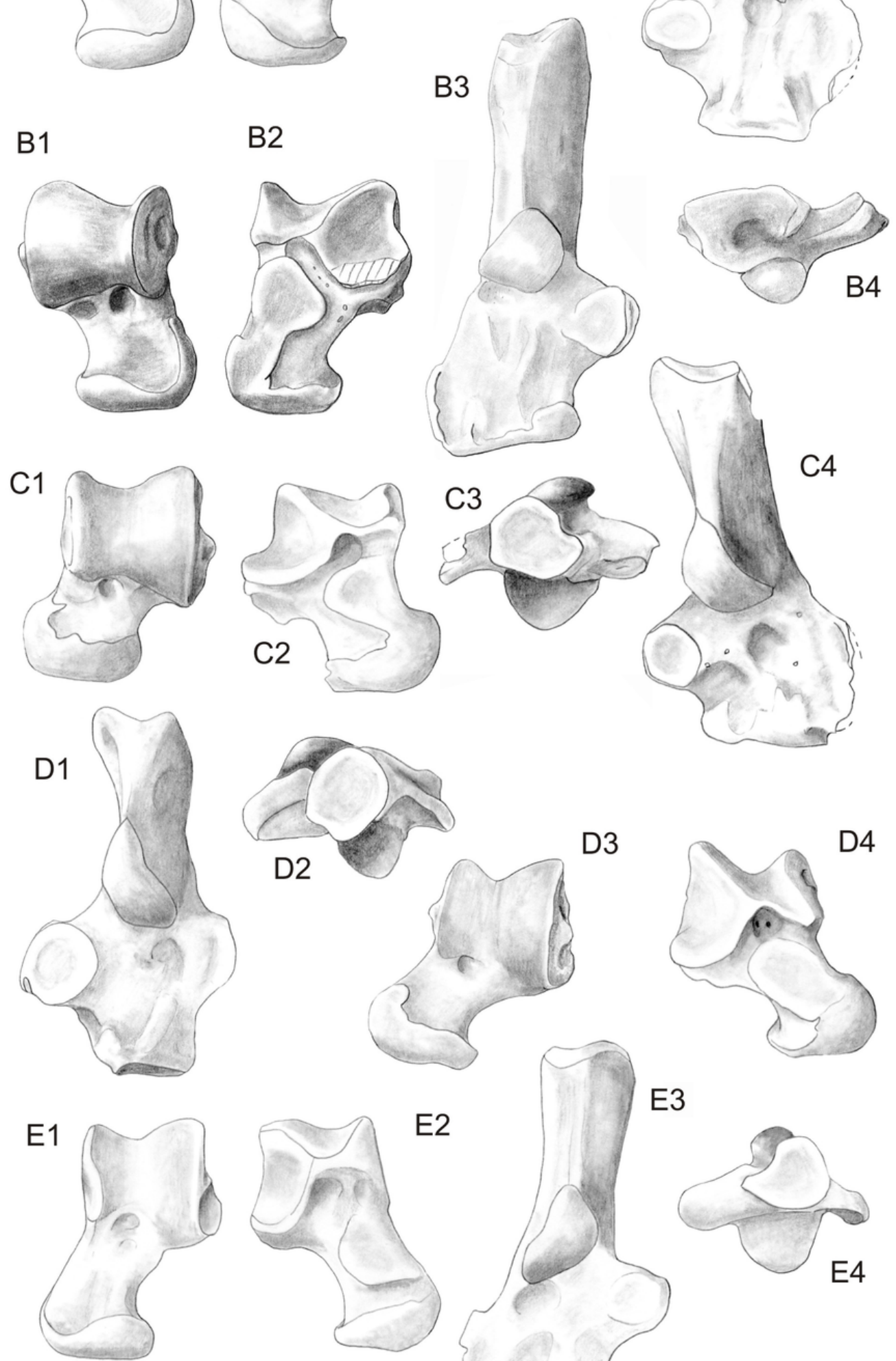

E2

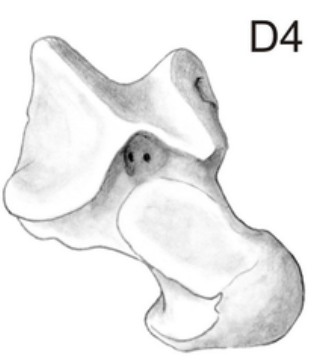

E3 


\section{Figure 9}

Drawing of the calcaneus and astragalus of a "typical" jumping rodent

Calcaneus and astragalus of Chinchilla lanigera illustrating jumping morphology. Numbers represent typical qualitative characters for this locomotory group, as well as most of the cursorial taxa studied here. (1) Neck (calcaneus) straight, and (2) of equivalent width with the anterior part of the bone. $\mathrm{CaCu}$ facet (3) oblique and (4) bean or crescent-shaped. (5) Peroneal process not developped and in distal or distal-most position. (6) Symetrical trochlea with a deep groove. (7) Neck (astragalus) slightly or not deflected medially. (8) Head narrow, with the AN facet developped dorsally. (9) Ectal facet projected laterally. (10) Sustentacular facet slender and antero-posteriorly oriented. (11) AmT facet developped on the plantar and/or medial side of the neck (astragalus). 

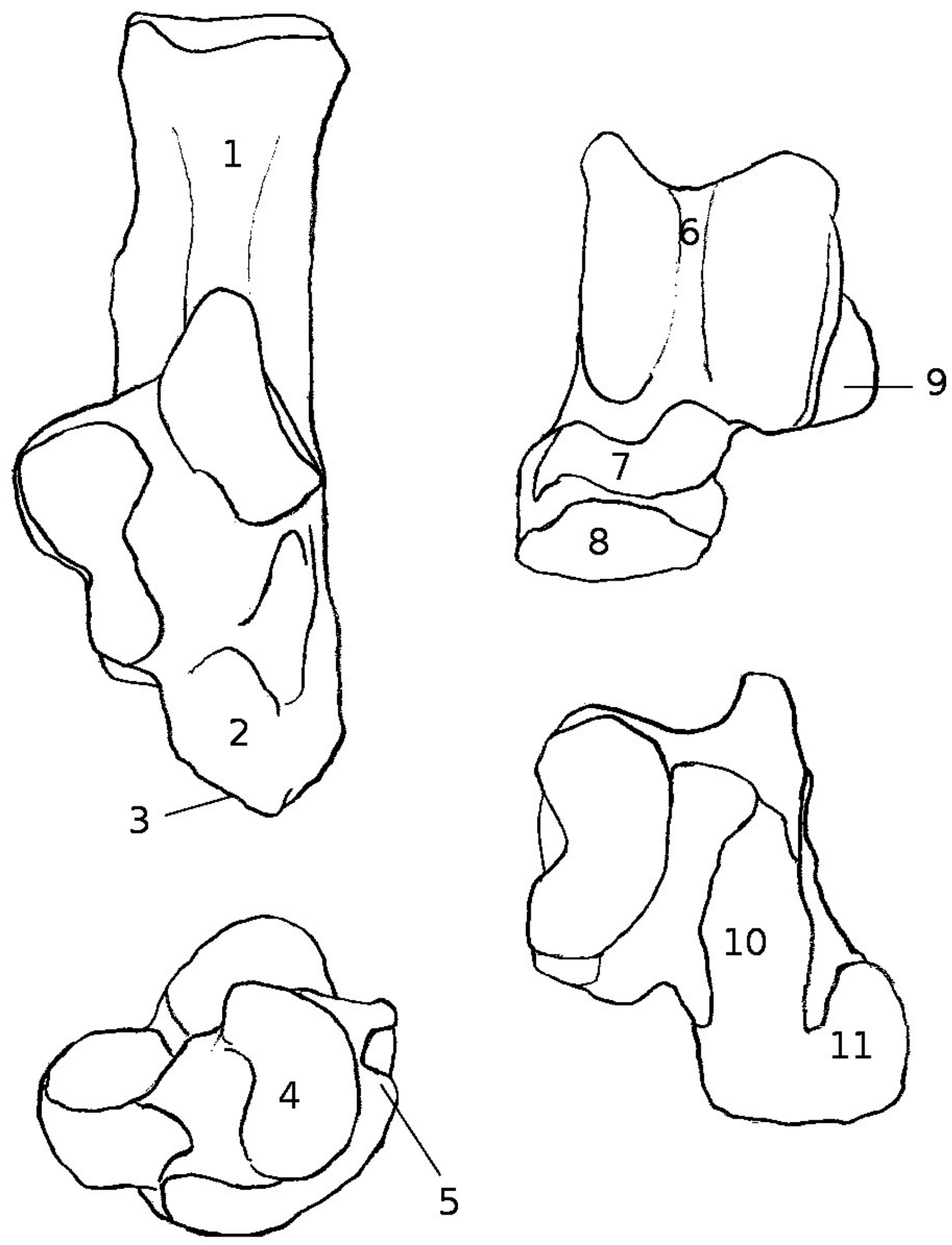


\section{Figure 10}

Drawing of the calcaneus and astragalus of a "typical" climbing rodent

Calcaneus and astragalus of Sciurus vulgaris illustrating arboreal climber morphology. Numbers represent typical qualitative characters for this locomotory group. (1) Slender and medially curved neck (calcaneus). (2) Peroneal process well-developped and in a posterior position. (3) Wide anterior part of the bone. Calcaneo-cuboid facet (4) perpendicular to the main axis of the bone and (5) of circular shape. (6) Asymetrical trochlea with a shallow groove. (7) Medially deflected neck (astragalus). (8) AmT facet developped on the dorsal side of the neck. (9) Wide and round head. (10) Sustentacular facet wide and oriented transversally. 

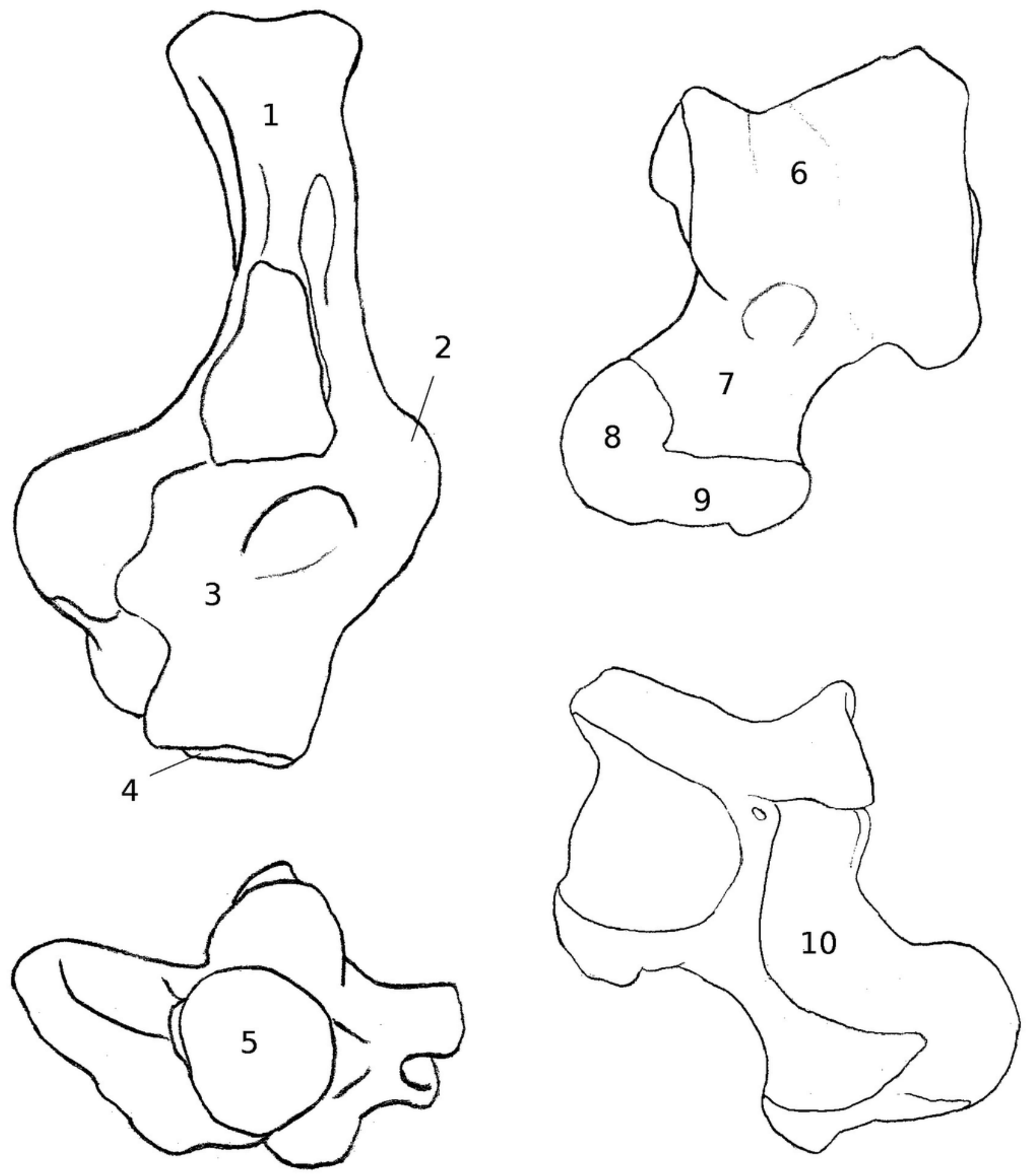


\section{Table $\mathbf{1}$ (on next page)}

Summary of specimens studied

Rodent specimens studied, their locomotor category and literature sources consulted. Fossil species are marked with an asterisk (*). Locomotory categories are numbered as follows : 1 : “jumping" ; 2 : “cursorial” ; 3 : "terrestrial generalist" ; 4 : “fossorial/semi-fossorial” ; 5 : "arboreal climber" ; 6 : "semi-aquatic" ; na designates fossil species, for which we try to assess the locomotion. 
 \\ Collection number \\ Locomotory} category

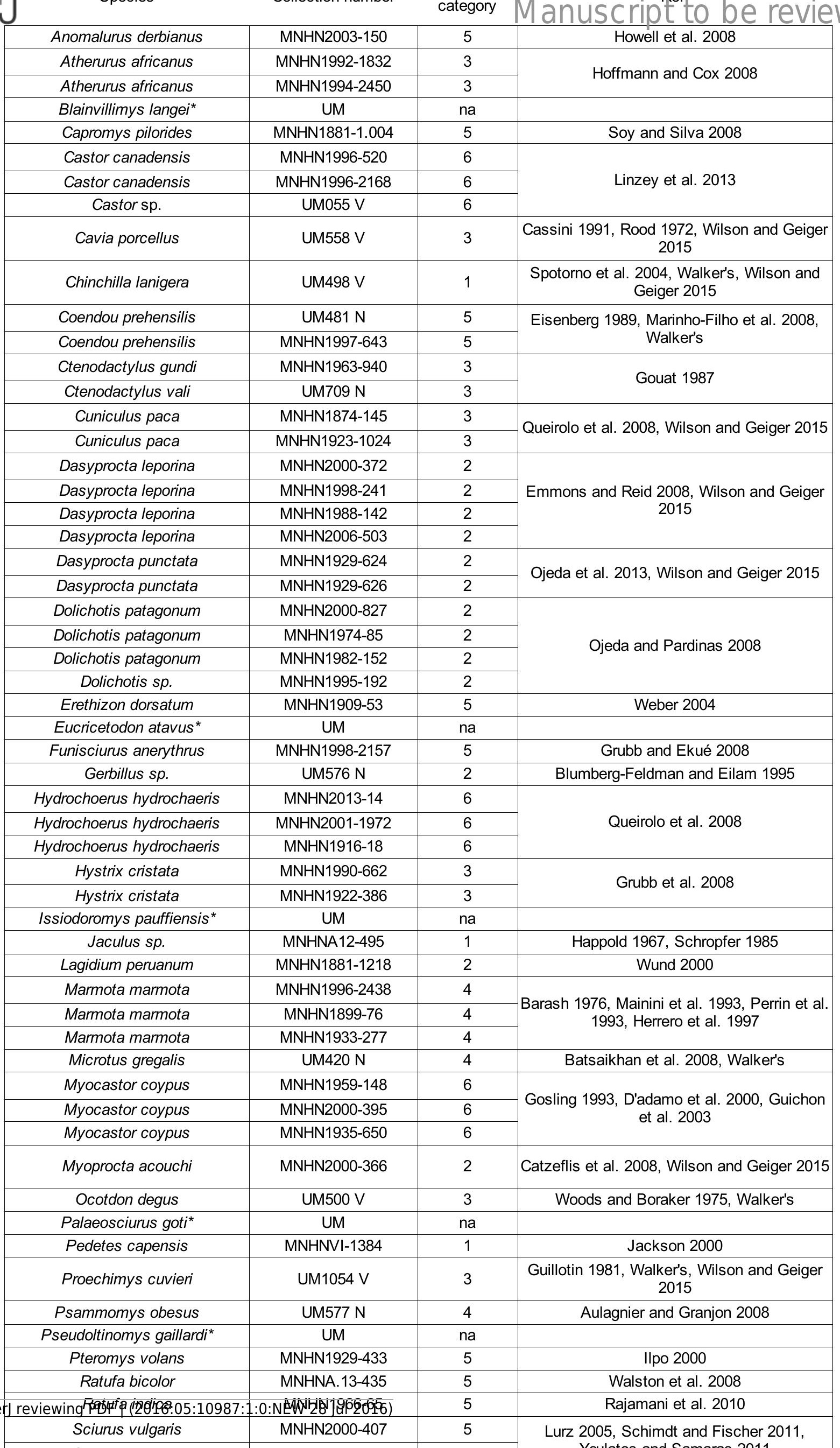




\section{Table 2 (on next page)}

Structure matrix of the LDA of the astragalus.

Correlation coefficients of variables with the LD functions are presented. Significant correlations are marked in bold. 
1

\begin{tabular}{|l|l|l|l|l|l|}
\hline & LD & LD2 & LD & LD & LD5 \\
\hline ABW & -0.10537176 & $\mathbf{- 0 . 5 0 0 9 8 8 5 6}$ & 0.046093587 & 0.013015596 & $\mathbf{- 0 . 4 6 2 1 0 4 4 0}$ \\
\hline ATL & -0.11995258 & $\mathbf{0 . 3 6 5 1 9 7 1 0}$ & 0.164739754 & $\mathbf{- 0 . 3 3 3 1 6 3 2 0 1}$ & $\mathbf{0 . 3 7 7 6 1 9 6 1}$ \\
\hline ATW & 0.26204140 & -0.15665090 & 0.276320246 & $\mathbf{0 . 6 4 9 2 8 5 7 2 0}$ & -0.26499805 \\
\hline EL & $\mathbf{0 . 3 2 7 7 3 8 2 8}$ & -0.02529528 & 0.261982032 & 0.191915531 & -0.32008916 \\
\hline EW & -0.05817710 & -0.12669810 & -0.241478230 & -0.274803114 & -0.22041763 \\
\hline HH & 0.16402700 & $\mathbf{0 . 4 5 0 9 7 5 3 1}$ & 0.303174467 & 0.011135147 & $\mathbf{- 0 . 5 2 5 3 1 9 9 0}$ \\
\hline HW & -0.04956075 & -0.01003520 & 0.270973137 & -0.110596893 & $\mathbf{0 . 5 2 3 6 4 0 7 5}$ \\
\hline LBH & $\mathbf{- 0 . 5 1 4 2 3 9 9 9}$ & -0.10762628 & 0.005310194 & -0.131664969 & $\mathbf{0 . 4 5 0 6 5 8 2 0}$ \\
\hline LTL & -0.11572577 & 0.07809347 & $\mathbf{0 . 3 7 0 1 6 7 0 9 7}$ & $\mathbf{0 . 3 8 6 0 9 3 6 6 4}$ & -0.05059842 \\
\hline MBH & $\mathbf{- 0 . 5 7 1 2 0 7 8 5}$ & $\mathbf{- 0 . 6 1 3 6 6 0 6 0}$ & -0.050626406 & 0.040909368 & 0.14008911 \\
\hline MTL & $\mathbf{- 0 . 6 5 1 2 1 4 1 7}$ & $\mathbf{- 0 . 3 4 5 3 2 6 1 9}$ & -0.293433734 & 0.323860009 & 0.07402242 \\
\hline NL & 0.29086529 & $\mathbf{0 . 3 9 5 0 2 4 4 9}$ & 0.234091001 & $\mathbf{- 0 . 4 0 3 3 1 8 4 2 0}$ & 0.03408407 \\
\hline SL & $\mathbf{- 0 . 3 3 2 6 7 6 2 2}$ & 0.15018611 & $\mathbf{- 0 . 6 7 3 4 2 4 3 3 0}$ & -0.143015501 & 0.23584098 \\
\hline SW & $\mathbf{0 . 6 5 4 6 0 6 5 4}$ & -0.01896417 & 0.118607900 & $\mathbf{0 . 3 3 8 4 2 4 1 7 1}$ & $\mathbf{- 0 . 3 2 9 0 0 7 9 9}$ \\
\hline TWa & $\mathbf{0 . 5 4 9 3 3 8 9 5}$ & -0.10780003 & $\mathbf{- 0 . 3 2 9 9 7 9 9 4 6}$ & -0.005278722 & 0.09038230 \\
\hline
\end{tabular}

2 


\section{Table $\mathbf{3}$ (on next page)}

Structure matrix of the LDA of the calcaneus.

As in Fig. 2A. 
1

\begin{tabular}{|l|l|l|l|l|l|}
\hline & LD1 & LD2 & LD3 & LD4 & LD5 \\
\hline CAL & $\mathbf{- 0 . 6 0 8 9 2 2 6}$ & 0.009437009 & 0.26903032 & 0.30657590 & 0.01131940 \\
\hline CCH & $\mathbf{0 . 4 3 6 5 3 9 8}$ & -0.225030318 & -0.06647538 & 0.21760746 & 0.21190580 \\
\hline CCW & $\mathbf{0 . 6 8 4 6 8 6 6}$ & -0.071509066 & -0.23823943 & -0.04327920 & -0.18043648 \\
\hline CPL & $\mathbf{- 0 . 3 8 3 2 5 9 2}$ & 0.180004165 & 0.24599583 & -0.32329036 & $\mathbf{- 0 . 3 5 5 4 2 3 4 7}$ \\
\hline CTL & $\mathbf{- 0 . 6 5 3 7 2 0 0}$ & -0.030370030 & -0.02745715 & $\mathbf{0 . 3 6 5 1 0 8 4 7}$ & 0.09558776 \\
\hline CTW & $\mathbf{0 . 7 9 3 6 0 1 1}$ & 0.010207707 & $\mathbf{- 0 . 3 5 3 4 2 2 9 1}$ & 0.24844656 & 0.21476611 \\
\hline EL & 0.1632429 & 0.153461556 & $\mathbf{0 . 4 4 1 5 7 5 8 9}$ & -0.16975778 & -0.02279185 \\
\hline EW & -0.1930453 & 0.053702045 & 0.21899552 & $\mathbf{- 0 . 3 6 5 2 1 5 1 0}$ & $\mathbf{- 0 . 4 6 2 5 7 4 2 2}$ \\
\hline MH & $\mathbf{- 0 . 6 3 7 1 1 6 4}$ & 0.216593121 & -0.04388484 & 0.04501014 & 0.32716889 \\
\hline NH & -0.1822259 & 0.295394822 & 0.30618512 & -0.17328258 & -0.02273043 \\
\hline NW & -0.2464843 & $\mathbf{- 0 . 3 7 9 2 6 2 3 3 9}$ & -0.30127783 & -0.11361849 & $\mathbf{0 . 5 8 6 0 2 0 7 8}$ \\
\hline PPL & 0.3166758 & -0.163289434 & 0.06851816 & 0.28356598 & -0.18724439 \\
\hline SL & 0.0306049 & $\mathbf{0 . 4 7 3 5 5 8 8 9 8}$ & $\mathbf{- 0 . 3 4 6 5 7 3 2 6}$ & -0.27026256 & -0.16754147 \\
\hline SW & $\mathbf{0 . 3 4 7 3 6 8 5}$ & -0.165810698 & 0.08090421 & -0.22729684 & 0.28674243 \\
\hline TH & $\mathbf{0 . 4 0 2 0 6 9 3}$ & 0.087112252 & -0.05230598 & 0.18863164 & 0.09423960 \\
\hline TWc & $\mathbf{- 0 . 3 8 2 6 4 4 5}$ & $\mathbf{- 0 . 4 7 9 3 3 5 9 5 4}$ & $\mathbf{- 0 . 3 7 8 8 2 0 4 8}$ & 0.29881183 & 0.16442349 \\
\hline
\end{tabular}

